\title{
A developmentally regulated chromosomal origin of replication uses essential transcription elements
}

\author{
Gregory T. Marczynski, Krista Lentine, and Lucille Shapiro ${ }^{1}$ \\ Department of Developmental Biology, Beckman Center, Stanford University School of Medicine, Stanford, California \\ 94305-5427 USA
}

Only one of the two chromosomes in the asymmetric Caulobacter predivisional cell initiates replication in the progeny cells. Transcription from a strong promoter within the origin occurs uniquely from the replication-competent chromosome at the stalked pole of the predivisional cell. This regulated promoter has an unusual sequence organization, and transcription from this promoter is essential for regulated (cell type-specific) replication. Our analysis defines a new class of bacterial origins and suggests a coupling between transcription and replication that is consistent with the phylogenetic relationship of Caulobacter to the ancestral mitochondrion.

[Key Words: Caulobacter; origin of replication; transcription; polar development; hemE]

Received March 23, 1995; revised version accepted May 9, 1995.

Caulobacter crescentus offers the opportunity to study the control of DNA replication in the context of a developmental cell cycle. The C. crescentus predivisional cell expresses a remarkable asymmetry that polarizes cellular components so that every cell division yields two distinct cell-types: a motile nonreplicative swarmer cell and a sessile replicative stalked cell. The swarmer cell later differentiates into a stalked cell to grow and divide asymmetrically (for recent reviews, see Newton and Ohta 1990; Brun et al. 1994). In addition to distinct surface morphologies, the progeny swarmer and stalked cells receive newly replicated chromosomes that have different sedimentation coefficients (Evinger and Agabian 1979; Swoboda et al. 1982; Gober et al. 1991a), differentially transcribed genes (Gober et al. 1991a,b; Wingrove et al. 1993), as well as different replicative abilities (Marczynski and Shapiro 1992).

The great diversity of bacteria implies that they have evolved sophisticated systems to coordinate DNA replication with their diverse modes of proliferation. Unfortunately, critical information is lacking for most bacterial species regarding the organization of their origins of replication and the coordination of replication with the cell cycle. The $C$. crescentus chromosome, as is the case for Escherichia coli and Bacillus subtilis, uses one origin of replication (Lott et al. 1987; Dingwall and Shapiro 1989; Marczynski and Shapiro 1992). When placed on a nonreplicating plasmid, the cloned $C$. crescentus origin (Cori) supports autonomous plasmid replication (Marczynski and Shapiro 1992). In contrast to other plasmids,

${ }^{1}$ Corresponding author. whose replication occurs in both swarmer and stalked cells (Marczynski et al. 1990), "Cori-driven" plasmid replication coincides with the initiation of chromosome replication in the stalked cell (Marczynski and Shapiro 1992), indicating that the cloned Cori DNA responds to the same regulatory factors as the chromosome. This provides a powerful system in which to study the molecular switch between chromosomes that are active or inactive for replication.

A cell's commitment to replicate its genome is analogous to its commitment to differentiate by transcribing specific genes, and both processes are thought to share similar regulatory principles. Studies in E. coli have provided a detailed description of a replication initiation process that requires the ordered assembly of replication proteins (DnaA, helicase, primase, DNA polymerase, and topoisomerase subunits), collectively termed the replisome (Kornberg and Baker 1992), at a unique origin sequence. Targeted replisome assembly is conceptually similar to the action of transcriptional enhancer elements that load and activate RNA polymerase and transcription factors at specific promoters (Mitchell and Tiian 1989; Kustu et al. 1991; Roeder 1991; Heintz et al. 1992). Transcriptional enhancer elements also appear to be auxiliary components of several viral origins of replication (DePamphilis 1988; Guo and DePamphilis 1992; $\mathrm{Li}$ and Botchan 1993) and at least one yeast chromosomal origin of replication (Marahrens and Stillman 1992).

We report the DNA sequence requirements and functional organization of the $C$. crescentus chromosomal origin and demonstrate that an origin-internal promoter is important for the regulation of DNA replication. Tran- 
scription from this promoter anticipates chromosome replication in the progeny cells and occurs preferentially at the stalked pole of the predivisional cell. Our results imply that the differential activity of transcription factors at the two poles affects the switch between replicating and nonreplicating chromosomes.

\section{Results}

Novel DNA sequence requirements of the $\mathrm{C}$. crescentus origin of replication

The cloned Cori supports autonomous plasmid replication, and Cori-directed plasmid replication coincides with the onset of chromosomal DNA synthesis (Marczynski and Shapiro 1992). These results imply that this DNA region contains cell cycle control elements that restrict chromosome replication to the stalked cells. To define the DNA sequences required for regulated replication in $C$. crescentus, we mutagenized the Cori region systematically (Fig. 1A). Randomly generated deletions with BamHI linker insertions (shown as boxes numbered
1-27), as well as site-directed linker insertions and basepair changes (shown as dagger signs $\mathrm{a}-\mathrm{h}$ ) were created throughout the Cori region. These mutated origins were introduced into $C$. crescentus on plasmids that cannot replicate without the functional Cori sequence, and replication function was assayed by scoring for Cori-plasmid maintenance. As illustrated for six selected Coriplasmids in Figure 1B,C, we observed three classes of Cori-plasmid maintenance, designated Rep +, Rep + / and Rep-. Mutated Cori-plasmids were designated Rep + when they were indistinguishable from unmutated Cori-plasmids by these criteria: high frequency transformation $\left(10^{6}-10^{7}\right.$ colonies/ $\mu$ g of DNA), a large colony morphology (Fig. 1B, plates 1,2), and efficient Cori-plasmid extraction from liquid cultures (Fig. 1C, lanes 1,2). Cori-plasmids designated as Rep + / - gave comparable transformation frequencies, but their colonies were tiny (Fig. 1B, plates 3,4 ), and their plasmid yields were low from liquid cultures (Fig. 1C, lanes 3,4). The extracted Rep $+/$ - plasmids not visible on ethidium bromide-stained agarose gels, and although Rep+
Figure 1. Mutations defining the $C$. crescentus origin of replication (Cori). (A) The region of $C$. crescentus chromosomal DNA that supports cell type-specific autonomous plasmid replication in C. crescentus and in vitro-generated mutations aligned with major sequence landmarks. The AT box indicates a 40 -bp region of high $(85 \%)$ AT content. Deletions/insertions (boxes 1-27) and sitedirected mutations (daggers $\mathrm{a}-\mathrm{h}$ ) are described precisely in Tables 1 and 2. (D) Mutations that allow DNA replication $\left(R e p+l_{i}\right.$ and open boxes represent mutations that do not allow DNA replication $(\mathrm{Rep}-)$ when this cloned region is assayed for autonomous replication, as described below. Likewise, the open daggers represent mutations that impair replication (Rep - or Rep $+/-1$, and the solid dagger represents a Rep + linker insertion (Table 2). (H) HindIII; (P) PstI; (Bg) BglII; (E) EcoRI; and (B) BamHI. (B) The Cori-plasmid replication assay as revealed by plating electroporated $C$. cres. centus cells on antibiotic selection plates. The following plasmids were tested: (Plate 1) Wild-type (Rep +) pGM946; (plate 2) deletion/insertion 22 (Rep +) pGM1022; (plate 3) targeted 8-mer base pair changes $(\mathrm{Rep}+/-$ ) pGM1031; (plate 4 ) targeted 9-mer base pair changes $(\operatorname{Rep}+/-)$ pGM1036; (plate 5) targeted DnaA box base pair changes (Rep - / pGM1038; (plate 6) deletion/insertion 8 (Rep -) pGM1008. Each plasmid ( 0 ng) was electroporated into $C$. crescentus strain LS 108 and plated on PYE medium containing $20 \mu \mathrm{g} / \mathrm{ml}$ of ampicillin. (C) The Cori-plasmid replication assay as demonstrated by Southern blot analysis of plasmids extracted from liquid cultures. Plasmids were extracted from the same strains shown in $B$, plates $1-6$, as described in Materials and methods, and plasmid preparations from equivalent cell numbers were digested with EcoRI, subjected to Southern blot analysis, hybridized with ${ }^{32} \mathrm{P}$-la beled vector DNA, and exposed to X-ray film for 30 $\min$.
$A$

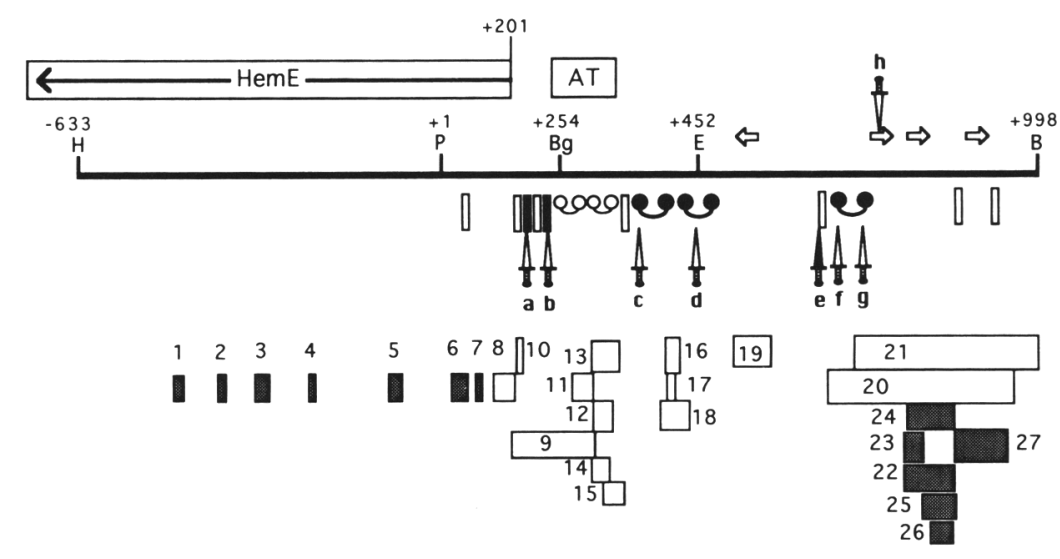

8 -mer $\begin{aligned} & \text { AAGCCCGG } \\ & 7 / 8 \text { or } 6 / 8 \text { match }\end{aligned}$

$\begin{array}{ll}9-\operatorname{mer} 2 & \text { GTTAA-.....-.TTAA } \\ 8 / 9 \text { match } & \end{array}$

DnaA Box $\Rightarrow$

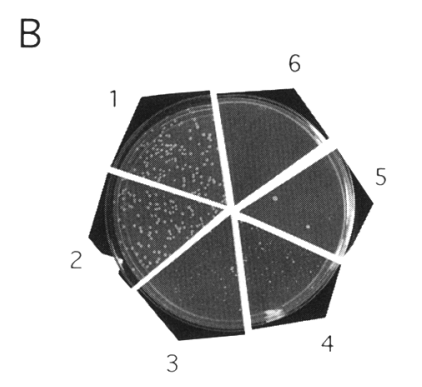

C

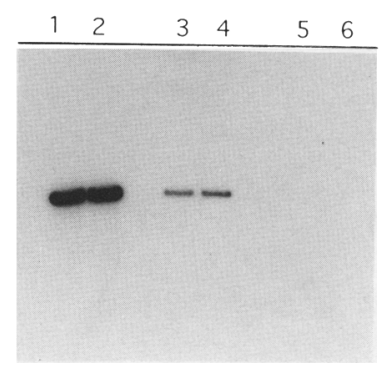


Developmentally controlled replication origin

Cori-plasmids were maintained indefinitely by subculturing, Rep + / - Cori-plasmids soon lost their autonomous replication state and integrated into the genome (data not shown). Cori-plasmids designated as Repgave low frequency transformation $\mid<10$ colonies $/ \mu \mathrm{g}$ of DNA) indistinguishable from background, and these few colonies could be accounted for by spontaneous acquisition of antibiotic resistance.

Cori-plasmids containing randomly generated deletions/insertions (Fig. 1A, boxes 1-27) all fall into either the Rep + or the Rep - classes. These mutations define an essential origin of replication whose left boundary lies between positions +137 and +198 , whose right boundary lies between positions +635 and +714 , and whose minimal length is between 437 and $577 \mathrm{bp}$.

DNA sequence motifs that are common to other bacterial origins of replication as well as those that are unique to Cori are contained within the essential DNA region defined by these mutations. At the E. coli chromosomal origin of replication, the DnaA protein, bound to specific sites (the "DnaA boxes"), promotes the unwinding of an adjacent AT-rich region (Bramhill and Kornberg 1988a; Kowalski and Eddy 1989) and subsequent replisome assembly at this site (Bramhill and Kornberg 1988b). The essential Cori region contains two DnaA box homologies that are potential binding sites for the DnaA protein (Yoshikawa and Ogasawara 1991; Zweiger and Shapiro 1994). Site-directed point mutations inside one Cori DnaA box (Fig. 1A, dagger h) abolished replication (Marczynski and Shapiro 1992). The other two potential DnaA box homologies fall within a Cori region that is not required for replication (deletions/ insertions 24-27). Also within the essential origin is an exceptionally AT-rich domain $185 \%$ AT between positions +251 and +290 ) that is present in other bacterial origins of replication (Bramhill and Kornberg 1988b).

The replication region also contains sequence motifs that are unique to Cori. Three perfect 9-mer motifs and two 8/9-bp 9-mer matches (spanning the AT-rich region) fall within the essential Cori region. Deletions/insertions 11, 29, and 30 (Figs. 1A and 3D; Table 1) demonstrate that the AT-rich region is essential. Targeted mutagenesis experiments demonstrated that all three perfect 9-mer motifs are essential for replication (Fig. I A, daggers $c, d, f, g$; Table 2). Adjacent to the AT-rich region is a cluster of four 8-mer motifs, and targeted mutagenesis experiments (Fig. 1A, daggers a,b; Fig. 3C, pGM1031 and pGM1032), as well as deletions/insertions 10 and 28 (Fig. 1A; Table 1) demonstrate that these motifs are essential for replication.

Two promoters overlap the essential C. crescentus origin of replication

An open reading frame that overlaps the essential Cori sequence was identified by DNA sequence analysis as a homolog of the E. coli hemE gene (GenBank accession no. U13664). Sequence analysis revealed a $44 \%$ amino acid identity and a $61 \%$ similarity to human uroporphy-
Table 1. Deletions and insertions inside the Cori region

\begin{tabular}{llcl}
\hline Mutation & $\begin{array}{l}\text { End points } \\
(\mathrm{bp})^{\mathrm{a}}\end{array}$ & Mutation & $\begin{array}{l}\text { End points } \\
(\mathrm{bp})^{\mathrm{a}}\end{array}$ \\
\hline 1 & $-504 / \mathrm{B} /-503$ & 16 & $+385 / \mathrm{B} /+420$ \\
2 & $-427 / \mathrm{B} /-426$ & 17 & $+397 / \mathrm{B} /+390$ \\
3 & $-337 / \mathrm{B} /-316$ & 18 & $+395 / \mathrm{B} /+454$ \\
4 & $-234 / \mathrm{B} /-230$ & 19 & $+511 / \mathrm{B} /+577$ \\
5 & $-72 / \mathrm{B} /-53$ & 20 & $+615 / \mathrm{B} /+911$ \\
6 & $+8 / \mathrm{B} /+60$ & 21 & $+635 / \mathrm{B} /+975$ \\
7 & $+97 / \mathrm{B} /+100$ & 22 & $+714 / \mathrm{B} /+814$ \\
8 & $+137 / \mathrm{B} /+198$ & 23 & $+714 / \mathrm{B} /+751$ \\
9 & $+185 / \mathrm{B} /+322$ & 24 & $+718 / \mathrm{B} /+836$ \\
10 & $+202 / \mathrm{B} /+212$ & 25 & $+764 / \mathrm{B} /+816$ \\
11 & $+270 / \mathrm{B} /+300$ & 26 & $+767 / \mathrm{B} /+812$ \\
12 & $+308 / \mathrm{B} /+330$ & 27 & $+813 / \mathrm{B} /+885$ \\
13 & $+297 / \mathrm{B} /+332$ & 28 & $+212 / \mathrm{H} /+244$ \\
14 & $+314 / \mathrm{B} /+345$ & 29 & $+254 /-/+287$ \\
15 & $+326 / \mathrm{B} /+353$ & 30 & $+259 /-/+274$ \\
\hline
\end{tabular}

${ }^{a}$ Numbers indicate the wild-type Cori base pair positions (Marczynski and Shapiro 1992) present on the left and right sides of each deletion/insertion shown in Figs. $1 \mathrm{~A}$ and $3 \mathrm{C}, \mathrm{D}$. (/B/) An intervening BamHI linker, GGGGATCCCC; $(/ \mathrm{H} /)$ an intervening HindIII linker, AAGCTTCC; $(/-/)$ no intervening DNA. Mutations 1-30 correspond to the Cori plasmid series pGM1001-pGM1030 in Table 3.

rinogen decarboxylase (UroD) (EC 4.1.1.37), an intermediate enzyme in heme biosynthesis (Romeo et al. 1986). The E. coli hemE gene encodes UroD, and we have adopted the bacterial nomenclature by convention (Bachmann 1990). UroD protein homology extends the entire length of the $C$. crescentus hemE gene (beginning at position +201 ), and we have performed protein fusion experiments to confirm that the HemE initiator AUG codon begins at position +201 (data not shown). The mutational analysis shown in Figure $1 \mathrm{~A}$ indicates that the $5^{\prime}$ portion of the hemE gene (beginning at position +201 ) overlaps an essential region of the $C$. crescentus origin suggesting that hem $E$ transcription from inside the Cori region may influence replication.

To examine the role of hemE transcription in the control of replication, we identified the hemE promoters and measured promoter activity during the $C$. crescentus cell cycle. The hemE promoters were located initially by constructing transcriptional fusions between a promoterless $l a c Z$ reporter gene and subclones from the Cori region (Fig. 2). Constructs $1-3$, which retain a large portion of the region 5' to hemE, produced between 2500 and 3000 Miller units. Constructs 4-8, which form a progressive deletion series, demonstrated promoter activity directly upstream of the hemE protein coding sequence. Construct 8 , which deleted all hemE 5 '-noncoding sequences up to +201 , lost all promoter activity. Constructs 9-12, where the lac $Z$ gene was inserted just upstream of the hem $E$ protein-coding sequence, produced progressively higher levels of $1 a c Z$ expression as rightward deletions removed the 8 -mer motifs. This suggests that expression from a strong promoter is impeded 
Table 2. Directed mutations inside the Cori region

\begin{tabular}{|c|c|c|c|}
\hline Mutation & Target & Replication & Description \\
\hline a & 8 -mer & $+1-$ & (see Fig. 3C, pGM1031) \\
\hline b & 8-mer & $+1-$ & (see Fig. 3C, pGM1032) \\
\hline c & 9-mer & - & [GGGTACCC] insert at $+395(\mathrm{HpaI})$ \\
\hline $\mathrm{d}$ & 9-mer & - & {$[\mathrm{AATT}]$ insert at $+447(E \mathrm{CoR})$} \\
\hline e & SmaI site & + & [GGGTACCC] insert at $+627(\mathrm{SmaI})$ \\
\hline f & 9-mer & $+1-$ & GTTAA $\ldots . .$. TTAA base pair changes at $+654-657$ to CGCTA $\ldots . . .$. TTAA \\
\hline $\mathrm{g}$ & 9-mer & - & [GGGTACCC] insert at $+667(\mathrm{Hpal})$ \\
\hline $\mathrm{h}$ & DnaA box & - & TGATCCACA base pair changes at +677 and +678 to TGAGACACA \\
\hline
\end{tabular}

Mutations a-h correspond to dagger symbols in Fig. 1A and plasmid series pGM1031-pGM1038 in Table 3.

by the 8 -mer cluster. Construct 12 , with lacZ inserted at the BglII site, produced $>11,000$ Miller units, but construct 13 , with only an extra 10-bp rightward deletion, produced only 2100 Miller units. Further rightward deletions past the AT-rich region reduced lacZ expression close to background levels (constructs 14-16). These results indicate that a strong promoter lies directly on the right side of the BgIII site inside the AT-rich region, and comparison of lac $Z$ expression from constructs 7 and 8 demonstrates a second weaker promoter on the left side of this BgIII site (between positions +201 and +254 ), because this region by itself produced $\sim 2000$ Miller units.

These observations are summarized by the model drawn at the bottom of Figure 2. A weak promoter contributes $\sim 2000$ Miller units and an upstream strong promoter contributes $\sim 10,000$ Miller units, of which all but $\sim 1000$ are impeded by downstream sequences overlapping the 8-mer cluster. A mechanism for impeding strong promoter expression is suggested by potential sec- ondary structure in the RNA leader sequences, as described below (Fig. 8A).

Primer extension assays were used to confirm this two-promoter model. A primer internal to the hemE protein-coding sequence revealed transcripts initiating at positions +201 and +251 (Fig. 3A). A primer at the start of the hemE protein-coding sequence revealed a single transcription start site at position $+251 / 252$ (Fig. 3B). These transcriptional start sites agree with the lac $Z$ reporter experiments shown in Figure 2 and additional $1 a c Z$ reporter experiments described below in Figure $3 \mathrm{C}, \mathrm{D}$.

The DNA sequences directly upstream of each hemE RNA start site are homologous to established promoters (Fig. 3C,D). Overlapping the 8-mer cluster is a consensus sequence derived from a number of $\sigma^{70}$-type C. crescentus promoters (B. Ely, pers.). This weak hemE promoter has correct spacing between the $+1,-10$, and -35 regions, and it matches the proposed -10 and -35 consensus in $8 / 9$ positions (Fig. $3 \mathrm{C}$ ). Its relative transcrip-
Figure 2. hemE promoters within the $C$. crescentus origin of replication mapped by lac $Z$ transcriptional reporter assays. A partial restriction map of the replication origin (Cori) is shown. Subclones of the Cori region were ligated into the pRK290 lacZ test plasmid (constructs 1-16 corresponding to lacZ-plasmid series pGM2001pGM2016 in Table 3). The lines show the extent of Cori DNA present in these constructs, and $\beta$-galactosidase $(\beta$-gal) activity is shown, in Miller units, to the right of each construct. Translational stop codons in all three reading frames precede the $l a c Z$ ribosome-binding site and prevent lacZ:: hemE protein fusions. The activities shown are the averages of at least three separate assays with S.D. $<10 \%$. The pRK290 lacZ test plasmid produced 250 Miller units without any subcloned DNA. Restriction sites and symbols are as presented in Fig. 1. The approximate locations of two promoters are shown at the bottom, along with an impedance region that reduces upstream transcription into $l a c Z$.

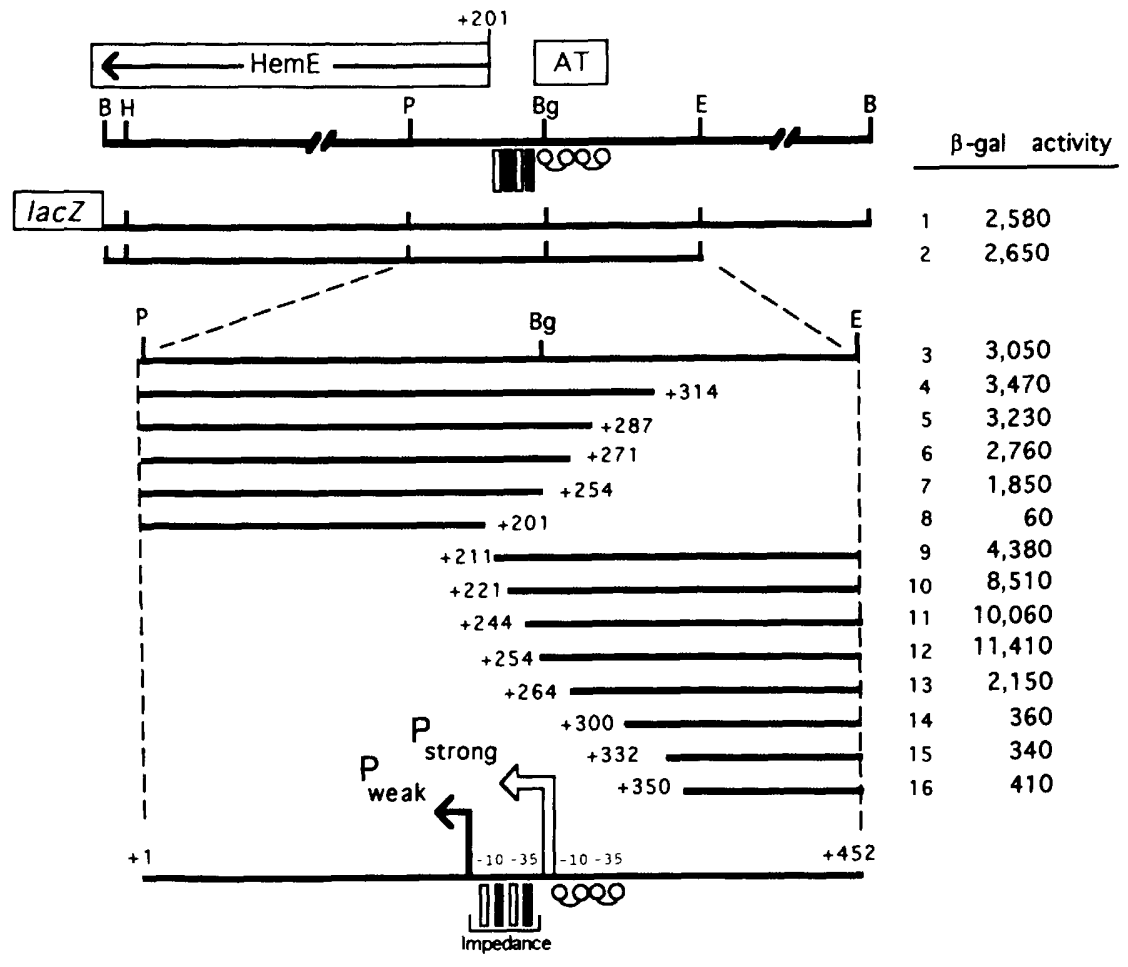



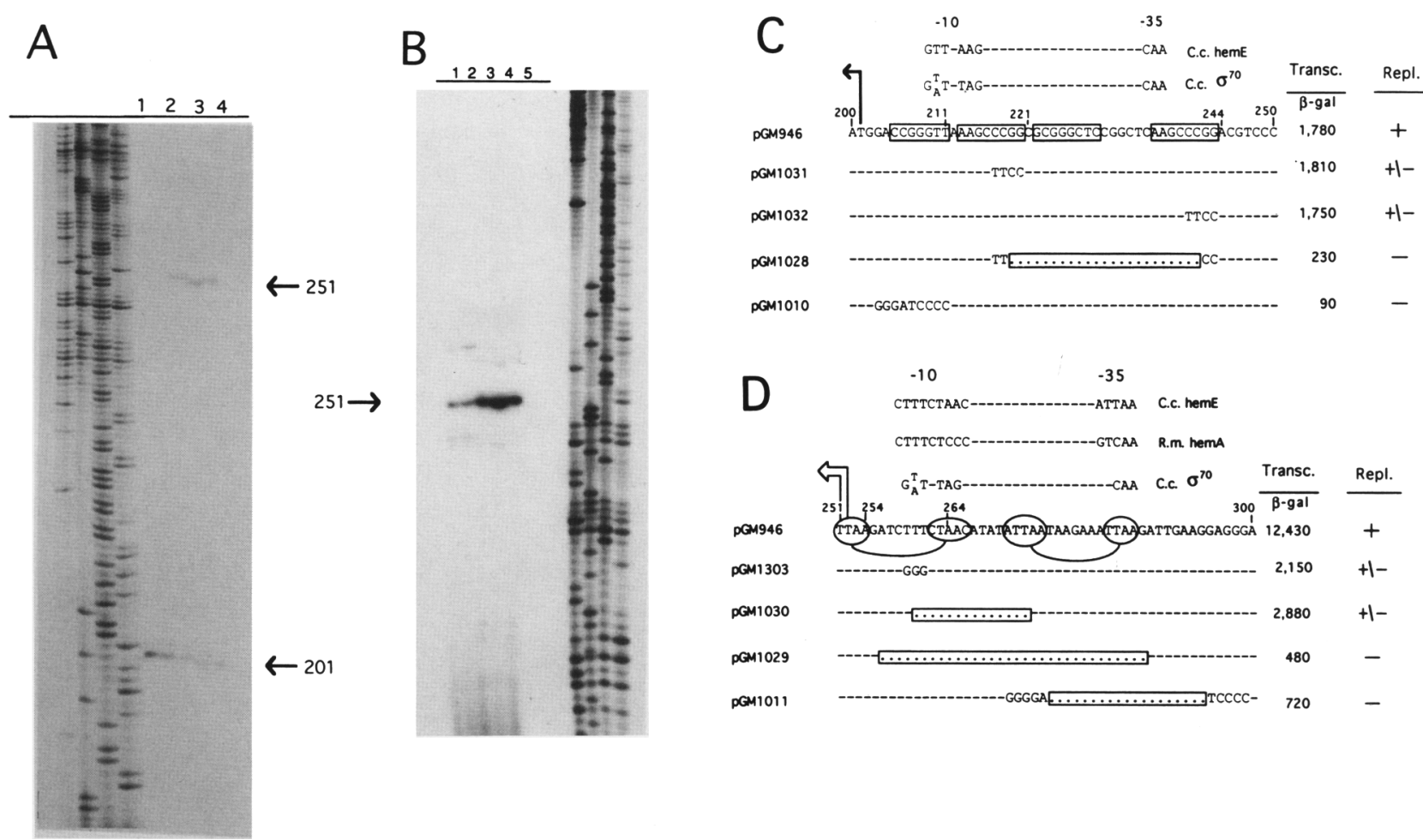

Figure 3. Sequences required for transcription and replication within the origin of replication. $(A, B)$ Primer extension analysis of both hemE promoters using ${ }^{32} \mathrm{P}$-labeled oligonucleotide primers complementary to an internal portion of the HemE-coding sequence $15^{\prime}$ position +120 through +137$)(A)$ and the amino terminus of HemE $\left(5^{\prime}\right.$ position +181 through +203$)(B)$. Lanes $1-4|A|$ and $1-5(B)$ present a series of primer extensions carried out at progressively increasing temperature using wild-type C. crescentus (NA1000) chromosomal RNA, as described in Materials and methods. Dideoxy-sequencing ladders served as the size standards. Numbered arrows mark the RNA start sites aligned with the Cori DNA base pair positions shown in $C$ and $D$. $(C, D)$ Sequences of two hemE promoters and analysis of transcriptional and replicative abilities of mutations in the promoter regions. The bent arrows position the primer extension results from $A$ and $B$ over the Cori DNA sequence directly upstream of hemE. Boxed sequences in $C$ show the four 8-mer motifs, and the connected ovals in $D$ show the two 9-mer motifs that are present on the wild-type plasmid pGM946. Established promoter sequences and the inferred hemE promoter - 10 and -35 elements are aligned above the wild-type sequence. Site-directed base pair changes and/or deletions present on mutant Cori-plasmids are shown below. Deletions are indicated by open boxes with dots, and base changes are shown with dashes to indicate the unchanged bases. Replication was assayed by electroporating these Cori-plasmids (containing the -633 to +998 Cori region) into C. crescentus strain LS108 and testing plasmid replication, as described in Fig. 1B,C. Transcription was assayed by testing Cori-plasmid subclones in the lacZ reporter system described in Fig. 2. In C, weak promoter transcription of each mutant origin was assayed by subcloning the PstI-BglII Cori DNA ( + l to + 254) into pRK290 lacZ; in $D$, strong promoter transcription was assayed by subcloning the AflII-EcoRI Cori DNA (+ 250 to +452) into pRK290 lacZ. These lacZ reporter plasmids correspond to pGM2021-pGM2028 in Table 3. The transcription assay results, presented in Miller units, are the averages of at least three separate experiments with S.D. $<10 \%$.

tion weakness is probably attributable to the one mismatch in the conserved base pair at position 213 (Fig. $3 \mathrm{C})$. The strong hemE promoter has a $6 / 9$-bp match to the same consensus, but it retains the most conserved base pairs at positions 261 and 263 in the -10 region, and at positions 285 and 286 in the -35 region (Fig. 3D). The -10 region of this promoter also has a $7 / 9$-bp match to the -10 region of the hem $A$ promoters of the closely related bacterium, Rhizobium meliloti (Leong et al. 1985).

We performed precise promoter mutation experiments to confirm the presence of the weak promoter within the four 8-mer motifs, and the strong promoter within the two 9-mer motifs. The weak promoter transcriptional start at position +201 (directly over the $\mathrm{A}$ of the hemE
AUG initiation codon) is unusual but not without precedent (Shean and Gottesman 1992). Only the weak promoter DNA (from PstI at +1 to BglII at +254 ) was used in the lacZ transcriptional reporter experiments shown in Figure 3C. Although the wild-type weak promoter DNA (from pGM946) produced 1780 Miller units, a deletion of the -35 region (pGM1028) and base pair changes that overlap the -10 region without changing the spacing (pGM1010) produced only 230 and 90 Miller units, respectively (Fig. $3 \mathrm{C}$ ). Because these mutations were predicted to impair the -35 and -10 promoter elements, respectively, clearly a functional promoter resides directly upstream of the hemE protein-coding sequence inside the 8-mer cluster.

In a similar manner, we demonstrated that a strong 
promoter overlaps two 9-mer motifs inside the AT-rich region. Only the strong promoter DNA (from $A$ flII at +250 to EcoRI at +452 ) was used in the lacZ transcriptional reporter experiments shown in Figure 3D. Although the wild-type strong promoter DNA (from pGM946/ produced 12,430 Miller units, the substitution of $3 \mathrm{G}^{\prime} \mathrm{s}$ for $3 \mathrm{~T}^{\prime} \mathrm{s}$ in the conserved -10 region (pGM1303), a deletion of the -10 region (pGM1029), an extensive deletion of both -10 and -35 region (pGM1029) and a deletion and base change in the -35 region \{pGM1011) all produced significantly lower Miller units (Fig. 3D). Because all four mutations are predicted to impair the -10 and/or -35 promoter elements, clearly a second promoter resides in the AT-rich region.

\section{Impaired transcription correlates with impaired replication}

All mutations that reduced hemE transcription, from either the weak promoter (Fig. $3 \mathrm{C}$ ) or the strong promoter (Fig. 3D), also impaired replication. This suggests that transcription is required for replication. However, this analysis is complicated by the overlap between promoter and replication elements. For the weak promoter, $8 / 9$ of the -10 and -35 promoter base pairs overlap the 8 -mer elements, and this precludes a mutational separation between these DNA sequences (Fig. 3C). However, as targeted 8-mer base pair changes (in pGM1031 and pGM1032) impair replication without reducing transcription from the weak promoter (Fig. 3C), we speculate that the four 8-mer motifs and not transcription from the weak promoter are required for Cori replication.

For the strong promoter, 6/9 of the C. crescentus $\sigma^{70}$ consensus promoter base pairs overlap the 9 -mer replication elements (Fig. 3D). The directed mutation analysis in Figure 1 demonstrated that the consensus 9-mer motifs are essential for autonomous Cori-plasmid replication. A comparison between the $C$. crescentus $\sigma^{70}$ consensus and the $R$. meliloti hem $A$ homology suggests that an important portion of the -10 promoter element lies outside the 9-mer elements, implying that a separation between replication and transcription elements is possible. Therefore, we changed the three conserved base pairs (at positions 259-261) from T's to G's (pGM1303). As shown in Figure 3D, comparison of the wild-type promoter in pGM946 with the -10 promoter mutation in pGM1303 revealed that replication is significantly impaired when strong promoter transcription is reduced from 12,430 to 2150 Miller units. Because the pGM1303 point mutations do not affect the 9-mer elements, we infer that transcription from the strong promoter is required for Cori replication. Apparently, transcription from the strong promoter contributes a replicative function that is separable from the replicative function contributed by the 9 -mer elements.

Cell-type-specific control of transcription within the C. crescentus origin of replication

To examine further the function of the two hemE promoters in the control of replication, their transcription was assayed during the developmental cell cycle. Swarmer cells were isolated and allowed to proceed synchronously through the developmental cell cycle, and at the indicated times, cells were removed and assayed for hemE transcription (Fig. 4). As described in Materials and methods, this assay measures mRNA transcription through the $l a c Z$ reporter gene. When positioned downstream of both hemE promoters, the lacZ gene was transcribed uniformly in all cell types (Fig. 4A). However, when the lac $Z$ gene was driven solely by the upstream strong promoter, the lac $Z$ reporter exhibited significant cell cycle variation (Fig. 4B). A PhosphorImager quantitation of this experiment is presented in Figure 4C. Na-

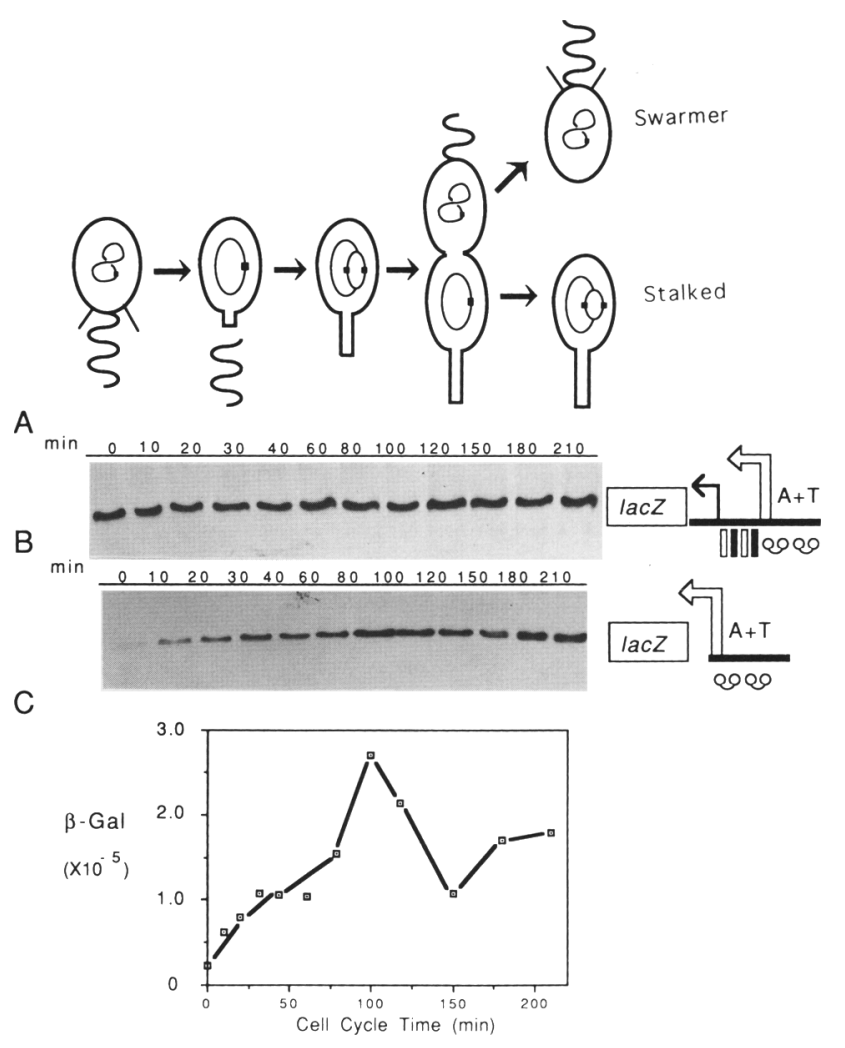

Figure 4. Transcription initiated from the two hemE promoters during the cell cycle. Samples of synchronized $C$. crescentus cultures bearing lac $Z$ transcription fusions to the hemE promoters were pulse-labeled with $\left[{ }^{35} S\right]$ methionine and immunoprecipitated with anti- $\beta$-galactosidase antibody as described in $\mathrm{Ma}$ terials and methods. Autoradiographs of $\beta$-galactosidase synthesis driven by both hemE promoters (Fig. 2, construct 3 ) and by the strong promoter alone (Fig. 2, construct 11) are shown in $A$ and $B$, respectively. $(C)$ The PhosphorImager quantitation of $B$. The ${ }^{35} S$-labeled $\beta$-galactosidase ( $\beta$-gal) units in $C$ are phosphorescence counts per protein band after a $12-\mathrm{hr}$ exposure to the PhosphorImager screen (Molecular Dynamics). Synchronous swarmer cells were released into fresh M2G media at $t=0 \mathrm{~min}$ and subsequently sampled for analysis of $\beta$-galactosidase synthesized from chimeric lacZ RNA at the times indicated above each lane. Cell division occurred at $t=150 \mathrm{~min}$ in both experiments. 
scent swarmer cells produced negligible amounts of $l a c Z$ mRNA, but as the swarmer cells developed into stalked cells, the level of $l a c Z$ mRNA increased. Peak transcription was observed at $\sim 100 \mathrm{~min}$, during the stalked cell phase. Transcription then decreased in the predivisional cells to $\sim 50 \%$ of its peak value. When cell division occurred, at $\sim 150 \mathrm{~min}$, and DNA replication resumed in the progeny stalked cells, transcription again increased from the strong promoter (Fig. 4B,C).

Because the hemE strong promoter is virtually inactive in the nascent swarmer cells, but highly active in the nascent stalked cells, we determined the precise time and polar position before cell division that this transcriptional switch occurs. Figure $4 \mathrm{C}$ indicates that strong promoter transcription decreased $\sim 50 \%$ in the predivisional cells, implying that either transcription decreased equally at both cell poles or that transcription decreased preferentially at the swarmer cell pole. To distinguish these possibilities, predivisional cells /containing the strong promoter $l a c Z$ transcriptional fusion/ were pulse labeled for 5 min with $\left[{ }^{35} \mathrm{~S}\right]$ methionine and chased with unlabeled methionine while they continued to grow and divide (Fig. 5A). The nascent swarmer and stalked cells were isolated, and the 116-kD $\beta$-galactosidase reporter protein was immunoprecipitated from equal amounts of ${ }^{35} \mathrm{~S}$-labeled cell extracts (Fig. 5A). The presence of the ${ }^{35} \mathrm{~S}$-labeled $\beta$-galactosidase in the progeny cells reports the subcellular compartment /swarmer pole vs. stalked pole) of the predivisional cell containing the chimeric mRNA at the time of the $\left[{ }^{35} \mathrm{~S}\right]$ methionine pulse. It has been demonstrated previously that the $\beta$-galactosidase protein shows no inherent bias toward either pole. However, if a flagellin gene promoter directs $l a c Z$ transcription, then in this protocol the $\beta$-galactosidase protein is recovered preferentially in the progeny swarmer cells (Gober et al. 1991b). As expected, the 25and $27-\mathrm{kD}$ flagellin proteins are synthesized exclusively at the swarmer pole of these same predivisional cells (Fig. 5A). In contrast, when the strong hemE promoter drives $l a c Z$, $\beta$-galactosidase synthesis occurs primarily at the stalked cell pole before cell division (Fig. 5A). This indicates that the strong promoter is transcribed primarily from the chromosome at the stalked pole before cell division.

Stalked pole-specific transcription of the strong hemE promoter might be attributable to selective activation at
A

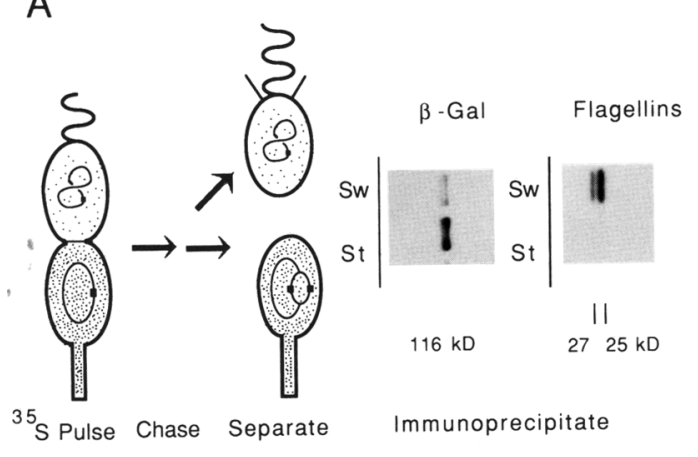

C

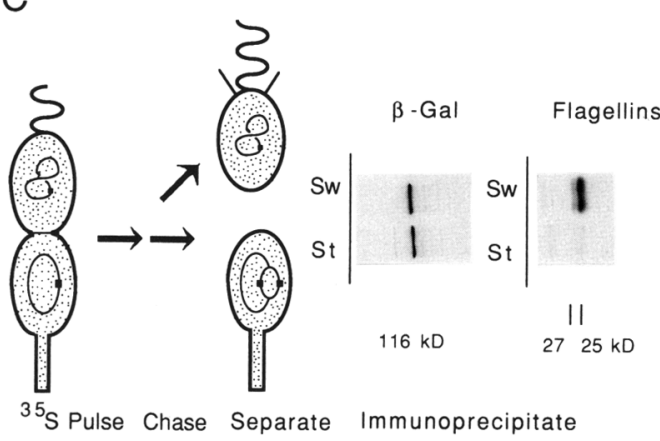

B

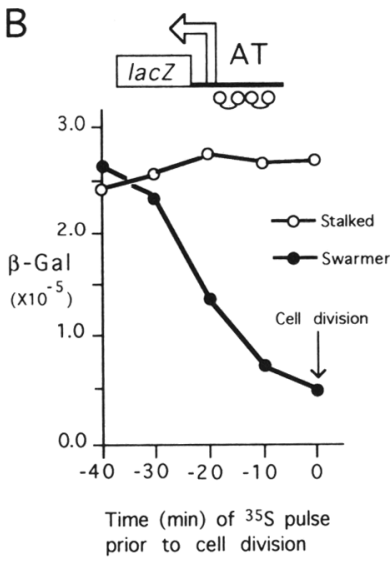

D

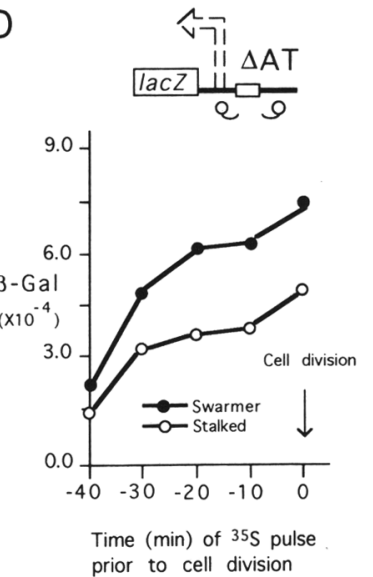

Figure 5. Stalked pole-specific transcription of the strong hemE promoter. (A) Protocol diagram and example of one assay of pole-specific hemE/lacZ transcription. Swarmer cells, bearing the $l a c Z$ transcription fusion to the strong hemE promoter (Fig. 2, construct 11), were allowed to proceed to the predivisional stage. These cells were then pulse labeled with $\left[{ }^{35} S\right]$ methionine for $5 \mathrm{~min}$ and allowed to divide in the presence of excess unlabeled methionine (chase period). Progeny swarmer (Sw) and stalked $(\mathrm{St})$ cells were isolated, $\beta$-galactosidase and, as a control, flagellin proteins were immunoprecipitated from equal amounts of ${ }^{35} \mathrm{~S}$-labeled protein extracts, as detailed in Materials and methods. $|B|$ Time course of swarmer pole and stalked pole transcription from the strong hemE promoter before cell division. The protocol described in $A$ was repeated, but the time of the pulse with $\left[{ }^{35} S\right]$ methionine was varied from 0 to $40 \mathrm{~min}$ before cell division. The relative amount of ${ }^{35} \mathrm{~S}$-labeled $\beta$-galactosidase in progeny stalked and swarmer cells was quantified by PhosphorImaging of immunoprecipitated proteins and graphed as shown. The ${ }^{35} \mathrm{~S}$-labeled $\beta$-galactosidase units in $B$ and $D$ are phosphorescence counts per protein band after a 12-hr exposure to the PhosphorImager screen (Molecular Dynamics). $(C, D)$ Loss of stalked polespecific transcription from a mutant strong hemE promoter. The pGM1030 lacZ transcriptional reporter from Fig. 3D was used, but otherwise these polar transcription assays are identical to those present in $A$ and $B$. 
the stalked pole or selective repression at the swarmer pole. To distinguish between these two mechanisms, we modified the polar transcription protocol shown in Figure $5 \mathrm{~A}$, by varying the time of the $\left[{ }^{35} \mathrm{~S}\right]$ methionine pulse between 0 and $40 \mathrm{~min}$ before cell division (Fig. 5B). The progeny swarmer and stalked cells were isolated, and the relative amount of reporter protein was quantitated by immunoprecipitation and ${ }^{35}$ S-labeled PhosphorImaging, as described in Materials and methods. Transcription at the stalked pole was found to remain constant, whereas transcription at the swarmer cell pole decreased before cell division (Fig. 5B). One interpretation of these transcription kinetics is that the hemE strong promoter is repressed selectively at the swarmer pole of the predivisional cell.

The preferential transcription of the hemE strong promoter at the stalked pole (Fig. 5A,B) is probably mediated by the two 9 -mer motifs that overlap both the -10 and -35 promoter elements (see Fig. 3D). The deletion in pGM1030 removes sequences from both 9-mer motifs while retaining significant transcription activity (Fig. 3D). If the 9-mer sequences contribute to the differential transcription of the strong promoter within Cori, then the mutated 9-mer sequences in pGM1030 should result in a loss of stalked pole transcription preference. Consistent with this hypothesis, the polar transcription experiments in Figure 5, C and D, which parallel those in the preceding panels for the wild-type promoter, demonstrate that this mutant promoter has lost all transcriptional preference for the stalked pole. The mutant promoter possesses a small but consistent transcription bias for the opposite swarmer pole (Fig. 5D). Therefore, stalked pole-specific regulatory sequences overlap the AT-rich region inside Cori. Although the experiment shown in Figure 5B suggests that a swarmer pole-specific repressor binds the 9-mer sequences, we cannot rule out the possibility that transcription is activated preferentially at the stalked pole. The experiment presented in Figure 5D shows that the pGM1030 mutation both decreased basal transcription and yielded equal transcription at both poles.

To confirm that stalked pole-specific transcription is a special property of the hemE strong promoter, we repeated the polar transcription protocol for each of four lac $Z$ transcription fusions that assayed the combined hemE promoters (Fig. 6A), the hemE weak promoter alone (Fig. 6B), the wild-type strong promoter alone (Fig. $6 \mathrm{Cl}$, and the pGM1030 mutant strong promoter alone (Fig. 6D). The ratio of ${ }^{35} \mathrm{~S}$-labeled protein recovered in stalked versus swarmer cells $(\mathrm{St} / \mathrm{Sw})$ as a function of the time of the pulse label before cell division is shown in each case. Most proteins, such as RNA polymerase $\left(\beta \beta^{\prime}\right)$ subunits, partition equally to both progeny cells and show a St/Sw ratio of $\sim 1.0$, whereas flagellin proteins partition exclusively to the swarmer cells (Gober et al. 1991 b) and show a St/Sw ratio of $<0.1$ (Fig. 6). Transcription from the combined hemE promoters, which includes the 8-mer impedance region (Fig. 6A), from the weak hemE promoter alone (Fig. 6B) and from the mutant strong promoter alone (Fig. 6D), showed no stalked pole bias. Only when $l a c Z$ transcription was driven by the hemE wild-type strong promoter alone did its mRNA accumulate preferentially at the stalked pole of the predivisional cell (Fig. 6C).
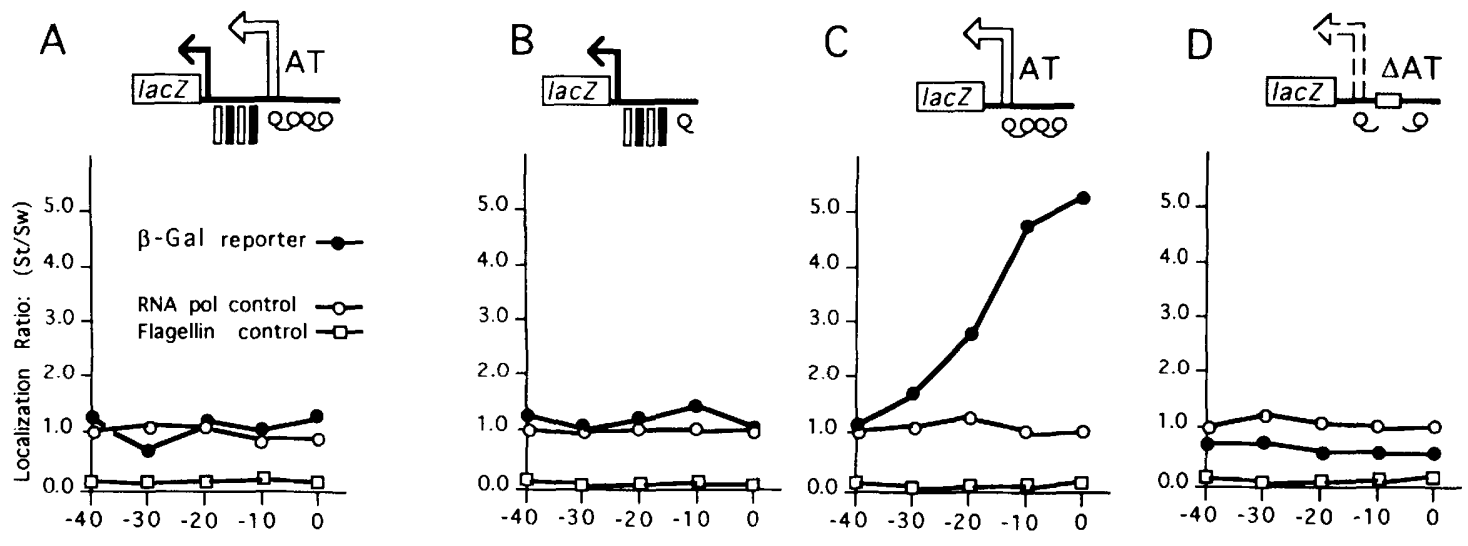

Time $(\mathrm{min})$ of ${ }^{35} \mathrm{~S}$ pulse prior to cell division

Figure 6. Only the wild-type strong hemE promoter exhibits stalked pole-specific transcription. $|A-D|$ Time courses before cell division of the polar localization ratio, defined as the ratio between transcription activity arising from the stalked and swarmer cell poles $(\mathrm{St} / \mathrm{Sw})$ of the predivisional cell. Each experiment used the following lac $Z$ transcription reporter constructs: $(A)$ the native two-promoter system; $(B)$ the weak promoter alone; $(C)$ the wild-type strong promoter alone; and $(D)$ a mutant strong promoter alone. These experiments were performed as described in Fig. 5 and used lac $Z$ transcriptional reporter constructs $3,7,11$ (Fig. 2), and the $1 a c Z$ construct from pGM1030 (Fig. 3D) shown symbolically in $A-D$, respectively. Equal amounts of ${ }^{35} S$-labeled protein extracts from progeny stalked cells and swarmer cells were analyzed for each time point. $\beta$-Galactosidase and flagellins $(25-$ and $27-\mathrm{kD}$ proteins) were assayed by immunoprecipitation, and the RNA polymerase ( $\beta \beta^{\prime}$ subunits) were observed directly on total cytosolic protein gels. Bands were quantified by PhosphorImaging and plotted as shown. 
Abolishing differential transcription from the two poles of the predivisional cell abolishes regulated replication in the progeny cells

The preceding experiments imply that stalked pole-specific transcription from the hemE strong promoter is required for stalked cell-specific replication. To test this hypothesis, cell type-specific Cori-plasmid replication was assayed using plasmid constructs with either the wild-type (stalked pole-specific, Fig. 5A,B) or the pGM1030 deletion mutant (nonspecific; Fig. 5C,D) hemE strong promoters, described above. For these experiments, we used a sensitive replication assay based on the observation that $C$. crescentus DNA is always fully methylated at the A nucleotide of the GANTC sequence on both DNA strands before replication (Zweiger et al. 1994). The GANTC methyltransferase is only present in late predivisional cells; therefore, DNA replication produces two hemimethylated molecules whose hemimethylated state persists until the end of the cell cycle. When the GANTC sequence overlaps a restriction endonuclease site, for example, ClaI or HincII, endonuclease cutting is blocked when both DNA strands are methylated, and the hemimethylated state is revealed by the acquired ability to cut at these sites on one of the two newly replicated DNA molecules. As reported previously, the chromosomal HincII site upstream of the dnaA gene is fully methylated in swarmer cells, and it becomes hemimethylated when swarmer cells differentiate into stalked cells (Zweiger et al. 1994). Because the C. crescentus dnaA gene is only $\sim 6 \mathrm{~kb}$ away from Cori, we used this HincII site to assay the initiation of chromosomal replication. Cori-plasmid replication was monitored similarly by inserting an oligonucleotidebearing overlapping ClaI and GANTC methylation sites.

Using this methylation assay, the replication kinetics of wild-type Cori-plasmids and mutant pGM1030 hemE strong promoter Cori-plasmids were compared with that of the chromosome during the swarmer to stalked cell transition period of the cell cycle. Swarmer cells containing these Cori-plasmids were prepared and analyzed as they differentiated synchronously into stalked cells. Both plasmid and chromosomal DNA were prepared, the percentage of hemimethylated molecules was determined by Southern blot analysis, and the corresponding percentage of replicated molecules was quantitated as detailed in Materials and methods.

The results presented in Figure 7 demonstrate that the Cori-plasmid with the mutant hemE strong promoter, unlike the wild-type Cori-plasmid, fails to initiate replication synchronously when swarmer cells differentiate into stalked cells. Chromosomal replication served as an internal control, and in both experiments (Fig. 7A,B), the chromosomes initiated replication with identical kinetics. However, although wild-type Cori-plasmid replication exhibited a steep sigmoidal curve that closely tracked the sigmoidal curve of the chromosome (Fig. 7A), the mutant Cori-plasmid exhibited a linear replication curve distinct from that of the chromosome and indicative of random replication. This linear accumulation of
A

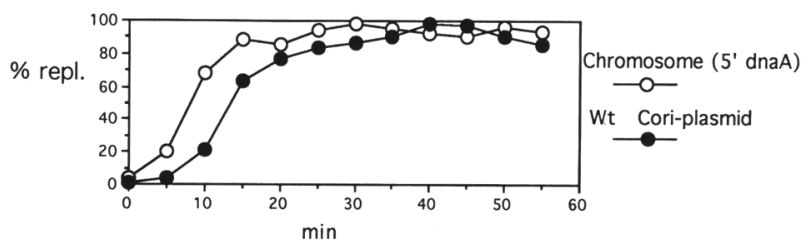

B

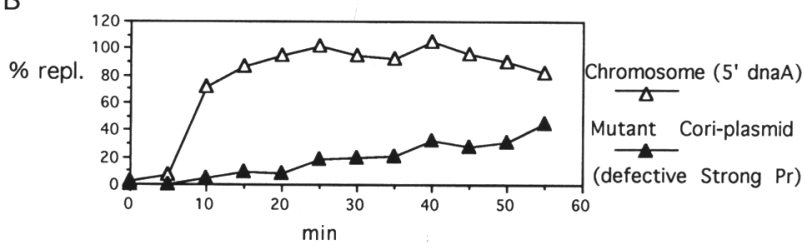

C

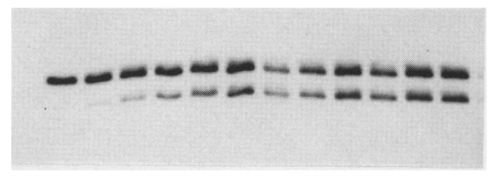

D

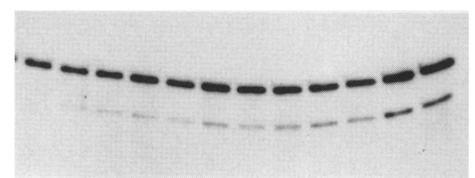

Figure 7. Wild-type and mutant Cori-plasmd replication was measured and compared to chromosomal replication by the methylation state assay reported previously (Zweiger et al. 1994). Wild-type Cori-plasmid (pGM946) and mutant hemE strong promoter Cori-plasmid (pGM1030) were modified so that they contained the RK2 par sequences /Roberts et al. 1990) between the HindIII and KpnI sites, and the following oligonucleotide sequence $5^{\prime}$-CTCGAGTCAGGCTCATCGATTCGATCGCAGCGGATCC-3', containing the ClaI and methylation site overlap, between the $\mathrm{XhoI}$ and $\mathrm{BamHI}$ sites. These are designated as pGM1064 and pGM1065, respectively (Table 3). Swarmer cells bearing these plasmids were isolated and allowed to differentiate into stalked cells by release into PYE medium. At the indicated times, both plasmid and chromosomal DNA were prepared separately and analyzed by Southern blot and PhosphorImaging techniques as described in Materials and methods. Chromosomal DNA was digested with HincII, and the Southern blots were hybridized with a $420-\mathrm{bp}$ piece of ${ }^{32} \mathrm{P}$ labeled DNA spanning the $5^{\prime}$ region of the $C$. crescentus dnaA gene (Zweiger and Shapiro 1994). Plasmid DNA was linearized with PstI and then redigested with excess ClaI. Cori-plasmid Southern blots were hybridized with ${ }^{35} \mathrm{P}$-labeled pGM946 vector DNA between the ClaI and PstI sites. $(A, B)$ The time course of the percentage of replicated molecules; chromosomal DNA $(O, \Delta)$ and plasmid DNA $(\mathbf{O}, \Delta)$ were obtained from analyses of images of the corresponding Southern blots. $(C, D)$ Autoradiographs of the corresponding wild-type and mutant Cori-plasmid Southern blots. The chromosomal DNA southern blots are not shown.

replicated plasmids implies that the mutant Cori-plasmids replicated at the same rate throughout most of the cell division cycle. In contrast, the sigmoidal curve implies that the wild-type Cori-plasmid replicated primarily during the brief 10 - to $20-\mathrm{min}$ period spanning the swarmer to stalked cell transition at the start of the 
DNA synthesis period. These wild-type Cori-plasmid replication results agree with those reported previously using a radioactive pulse-labeling method to assay replication (Marczynski and Shapiro 1992). Because the only difference between the wild-type and mutant Cori-plasmids is a 14-bp deletion that abolishes stalked pole-specific transcription in the predivisional cell (Figs. 5C,D and $6 \mathrm{D}$ ), we conclude that stalked pole-specific transcription from the hemE strong promoter is required to regulate replication in the progeny cells.

The stalked pole-specific hemE RNA originating from within the origin of replication is not translated

The 5'-leader sequence of the strong hemE promoter mRNA has the potential to form secondary structures that effectively bury the hemE AUG initiation codon and block ribosome binding (Fig. 8A). The majority of the base pairs in this RNA structure are formed by the four 8 -mer motifs. The $5^{\prime}$ end of the downstream weak promoter hemE mRNA lacks this structure, and initiates transcription at the start of the AUG for the HemE cod- ing sequence. Although this hemE mRNA lacks a Shine and Dalgarno (S.D.) sequence, it possesses a "downstream box" that is complementary to a region of the $C$. crescentus 16S rRNA (Fig. 8A), as is the case for the $\lambda$ phage $c$ I gene (Shean and Gottesman 1992). The proximity of the hemE downstream box to the AUG and the presence in C. crescentus $16 \mathrm{~S}$ rRNA of a domain utilized for these base pairings are directly analogous to several documented $E$. coli downstream boxes (Sprengart et al. 1990; Shean and Gottesman 1992). These considerations suggest that HemE translation might occur primarily from the weak promoter mRNA.

We confirmed this hypothesis by measuring protein synthetic rates from transcripts originating from the two hemE promoters. The results in Figure $8 \mathrm{~B}$ indicate that hemE translation derives primarily from the weak promoter mRNA and that most strong promoter mRNA molecules are not translated. This could be attributable to several factors, including premature termination or inability to access the AUG when the transcript initiates at the strong promoter. Comparison of hemE::lacZ fusion protein synthesis rates from constructs 1 and 2 re-

A

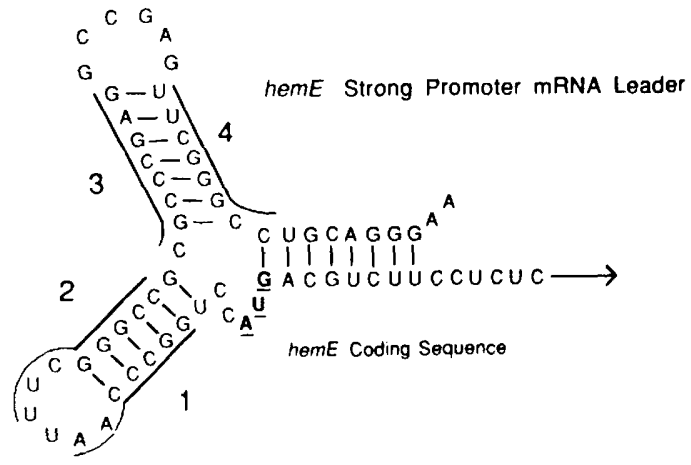

B
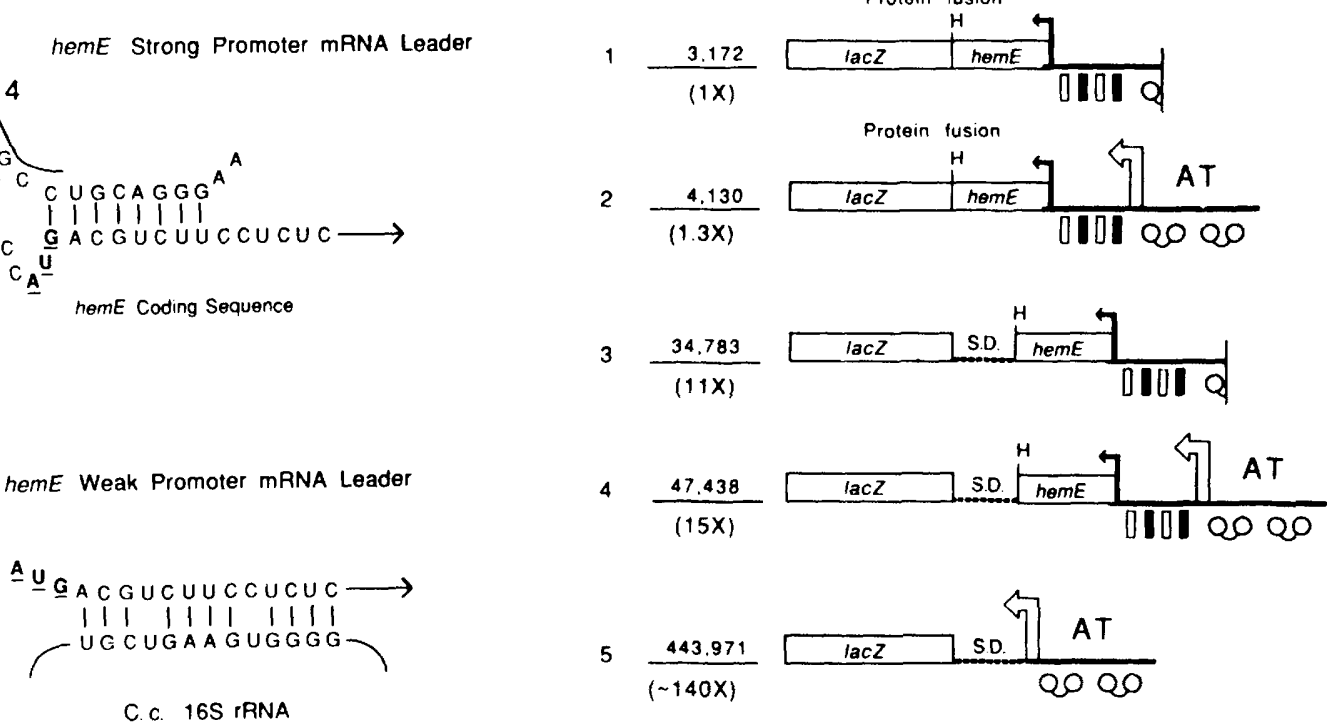

Figure 8. Translational efficiency of transcripts originating from the strong and weak hemE promoters. $|A|$ Potential RNA structures formed by mRNA initiating from either the hemE strong promoter or the downstream weak promoter. Base-pairing across the 8-mer motifs (numbered 1-4) in the leader mRNA originating from the strong promoter might block ribosome access to the AUG start codon. RNA sequences downstream of hemE AUG (i.e., the downstream box, Cori positions +198 through +186 ) might align ribosomes on the weak promoter mRNA lacking a S.D. site by base-pairing with C. crescentus $16 \mathrm{~S}$ rRNA from positions 1498 through 1486 (Ely 1992), as is observed for some $E$. coli (Sprengart et al. 1990) and bacteriophage $\lambda$ (Shean and Gottesman 1992) genes. (B) The mRNA originating from the strong hemE promoter is translated inefficiently. C. crescentus strains NA1000 containing constructs $1-5$, corresponding to plasmids pGM4001-pGM4005 in Table 3, were pulse-labeled with $\left[{ }^{35} S \mid\right.$ methionine, and equal amounts of ${ }^{35} \mathrm{~S}$-labeled protein extracts were immunoprecipitated with anti- $\beta$-galactosidase antibody. To aid the comparison of relative protein synthetic rates, the immunoprecipitated proteins were separated on a single polyacrylamide gel, and the resulting bands were quantitated by PhosphorImaging. The indicated numbers show protein synthesis units expressed as PhosphorImaging counts per band obtained after a 24-hr exposure to the PhosphorImaging screen (Molecular Dynamics). To normalize for transcription termination sequences, we compared constructs with the same lengths of hemE-coding sequence, between the HindIII site $(-633)$ and the AUG start codon (constructs 1-4). S.D. is the efficient Shine and Dalgarno site directing lacZ translation; other symbols are as in Fig. 1A. 
veals that most hemE translation is directed by the weak promoter, because addition of the strong promoter only increases protein synthesis from 3172 to 4130 Miller units. This is a very small increase, considering the relative strengths of these promoters. When the activities of constructs 1 and 2 are compared with that of constructs 3 and 4, it is evident that hemE translation from its native ribosome-binding sites is not very efficient, because a S.D. sequence provided by the lacZ reporter gene increased the rate of protein synthesis $\sim 10$-fold. The addition of the strong promoter to the weak promoter in constructs 3 and 4 also provided a disproportionally small increase in $l a c Z$ protein synthesis from 34,783 to 47,438 Miller units. Although the strong promoter's contribution to downstream protein synthesis is relatively minor in constructs 2 and 4 , its full protein synthetic potential is revealed in construct 5 where the 8-mer motifs are deleted and an efficient S.D. sequence is provided by the lac $Z$ reporter gene. Construct 5 demonstrates that the strong promoter can drive as much as 443,971 units of lac $Z$ protein synthesis, but that in its normal context the strong promoter only contributes $\sim 1000$ units (cf. constructs 1 and 2). Apparently, most transcripts that initiate from the strong hemE promoter do not contribute significantly to hemE gene expression. Presumably this RNA serves a replicative function.

\section{Discussion}

The $C$. crescentus predivisional cell exhibits a striking asymmetry that yields morphologically distinct progeny whose chromosomes have different replicative fates. Although the swarmer cell delays replication, the stalked cell initiates replication of the entire chromosome from a single origin and replication proceeds bidirectionally at a uniform rate until completion (Lott et al. 1987; Dingwall and Shapiro 1989; Marczynski and Shapiro 1992). Apparently, control mechanisms for replication initiation act asymmetrically in the predivisional cell, and we have focused our studies on the cloned C. crescentus origin of replication (Cori). Mutation analysis demonstrated that, in addition to anticipated features such as an AT-rich region and DnaA boxes, Cori contains novel replication elements such as 8 -mer and 9-mer motifs that are also essential for replication (Fig. 1). Interestingly, both 8-mer and 9-mer motifs are clustered in the $5^{\prime}$ region of the hemE gene, whose unusual transcription and translation properties are summarized in Figure 9A.

From our analysis, we conclude that replication is coupled to transcription from the strong hemE promoter originating from inside Cori. Seven major experimental results support this conclusion. (1) The $5^{\prime}$ region of the hemE gene overlaps the essential Cori replication region (Fig. 1). (2) Two hemE promoters intimately overlap repeated 8-mer and 9-mer motifs that are essential for replication (Figs. 2 and 3). The two 9-mer motifs that overlap the -10 and the -35 regions of the strong promoter are also present at three additional places inside Cori where their integrity is essential for replication. (3) Mu-

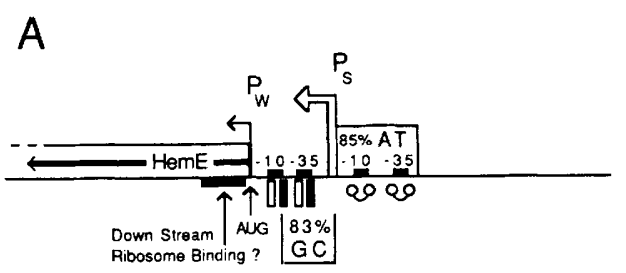

B

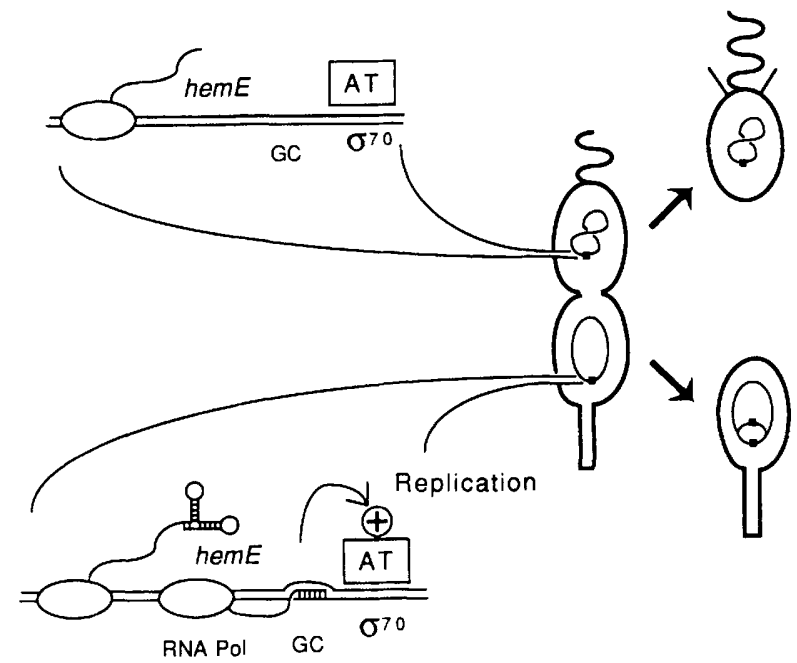

Figure 9. (A) Organization of the hemE $5^{\prime}$ region within the $C$. crescentus origin. The symbols are as shown in Fig. 1A. (B) A model indicating selective transcription from the hemE strong promoter on the chromosome in the stalked portion of the predivisional cell. We propose that transcripts from the strong promoter potentiate replication in the stalked cell chromosome, perhaps by forming RNA-DNA hybrids inside the Cori region.

tations that decrease promoter activity also impair replication (Fig. 3C,D). (4) Targeted mutagenesis that decreases strong promoter transcription (without changing the overlapping 9-mer motifs) impairs replication, implying that transcription is required for replication (Fig. 3D). (5) Translation of the HemE protein is significantly under-represented in comparison to the activity of the strong hemE promoter, implying that most transcripts initiating from the strong hemE promoter are not translated and presumably serve an alternative replicative function (Fig. 8B). (6) There is preferential transcription from the strong hemE promoter in the stalked cell pole of the predivisional cell and in the nascent stalked cell (Figs. 4B,C, 5A,B, and 6C). Therefore, transcription from the strong promoter anticipates chromosome replication. (7) When transcription from this strong promoter is impaired so that it is transcribed comparably at both poles (Figs. 5C,D and 6D), the control of replication is lost in the progeny cells (Fig. 7). We propose that preferential transcription from the strong promoter establishes a polarity in the predivisional cell that generates progeny whose chromosomes have different replicative fates (Fig. 9B). 
Polarized transcription in the C. crescentus predivisional cell requires a special transcriptional control system. Although most expressed genes are transcribed from both chromosomes in the predivisional cell, four flagellar promoters are known to be transcribed selectively at the swarmer pole (Gober et al. 1991a,b; Gober and Shapiro 1992). We observed that the strong hemE promoter decreases transcription at the swarmer pole, whereas stalked pole transcription remains constant during the predivisional cell period (Fig. 5B). This suggests that differential transcription from the strong promoter is attributable either to swarmer pole-directed repression or to stalked pole activation. The promoter deletion in pGM1030 (Fig. 3D), which affects both 9-mers, simutaneously yielded equal transcription at the swarmer and stalked poles (Figs. 5C,D and Fig. 6D) and eliminated normal replication control in the progeny cells (Fig. $7 \mathrm{~B}, \mathrm{D})$. Therefore, we suggest that a regulatory protein binds differentially to the two 9-mer motifs that overlap the -10 and -35 regions of the strong hemE promoters in the predivisional cell. Recent results indicate that a response regulatory element protein that acts at multiple points of the C. crescentus cell cycle binds to the 9-mer motifs in the strong hemE promoter (G. Marczynski, K. Quon, and L. Shapiro, unpubl.).

The activation of replication by transcription was originally encountered in the $E$. coli $\lambda$ phage and the $E$. coli chromosomal replication systems (for review, see Baker and Wickner 1992). In both cases, transcription is required for replication, although RNA polymerase probably does not actually synthesize a primer for DNA polymerase (Ogawa et al. 1985; Baker and Kornberg 1988). These systems contrast with plasmid ColE1 (Masukata and Tomizawa 1990) and mitochondrial DNA replication (de Zamaroczy et al. 1984; Schinkel and Tabak 1989; Clayton 1991), where RNA polymerase synthesizes the rate-limiting RNA primer for DNA polymerase. Plasmid ColE1 copy number control is dependent on a complex interplay between the secondary structure of the primer RNA and competition between annealing to an antisense RNA repressor or complementary DNA inside the ColE1 origin (Kues and Stahl 1989). Transcription from the Cori strong promoter through the 8-mer cluster blocks HemE translation (Fig. 8B), presumably by forming an RNA secondary structure in the leader sequence that blocks ribosome binding (Fig. 8A). By analogy to ColE1 plasmids, we speculate that this RNA structure has an additional replicative role inside Cori. The majority of the base pairs in this structure form by virtue of the 8 -mer motifs, and mutations inside the 8-mer cluster impair replication (Fig. 3C). We speculate that the 8-mer motifs are RNA structural elements, whereas the 9-mer motifs are DNA-binding sites for new replication proteins.

We also speculate that the C. crescentus hemE promoter/origin overlap represents an ancestral counterpart to the mitochondrial RNA-primed origin. Both C. crescentus and the ancestral endosymbiont that gave rise to the modern mitochondrion are members of the $\alpha$-subdivision of purple bacteria (Yang et al. 1985; Woese 1987;
Schmidt et al. 1991; Stahl et al. 1992). Promoters like the strong hemE promoter, which are not coupled to genetic expression, are characteristic of yeast mitochondrial origins of replication (de Zamaroczy et al. 1984; Schmitt and Clayton 1993). The sequences downstream of the strong hemE promoter are $83 \%$ GC (Fig. 9A), and our mutations define this GC block as absolutely essential for replication (Fig. 3C). As shown in Figure 9B, we propose that this GC block may clamp the 5 ' end of the hemE mRNA preferentially at the stalked pole of the predivisional cell, where we have demonstrated that this promoter is transcribed preferentially before cell division. This clamping mechanism and the proximity of the GC block to the RNA start site are directly analogous to mitochondrial replication origins (Schmitt and Clayton 1993|. A persistent hemE RNA-DNA hybrid might serve as a heritable replication determinant to preferentially stimulate replication in the progeny stalked cell.

The mechanism for stimulating replication may involve establishing a rate-limiting primer (by RNase $\mathrm{H}$ cleavage) or destabilizing the adjacent $85 \%$ AT region, as implied in Figure 9B. Short RNA/template hybrids (Rloops) located at or near the $E$. coli origin stimulate replication in vitro, apparently by promoting DNA melting under suboptimal conditions (e.g., low supercoiling, or high HU chromatin protein concentration) that would otherwise inhibit the DnaA-dependent strand-separating reaction at the AT-rich region (Baker and Kornberg 1988; Skarstad et al. 1990). The E. coli mioC and gidA genes flank the origin, but their promoters are separate from the minimal E. coli origin (Oka et al. 1980, 1984). However, their transcription can influence replication significantly under special circumstances (Asai et al. 1990; Lobner-Olesen and Boye 1992). Recently, it has been demonstrated that gidA and mioC transcription is modulated during the $E$. coli cell cycle such that gidA transcription increases while mioC transcription decreases before the initiation of replication (Theisen et al. 1993; Ogawa and Okazaki 1994). Also, and perhaps more similar to our results, transcription from specific promoters inside the $E$. coli origin may cooperate with the DnaA protein to unwind the AT-rich region (Asai et al. 1992). Our observations on transcription within the C. crescentus origin of replication imply that it may use general transcriptional control mechanisms to polarize both replication and morphogenesis in the asymmetric predivisional cell. Although, other mechanisms can be proposed, currently we favor the model presented in Figure $9 \mathrm{~B}$ because it uses established biochemical properties and it makes experimentally testable predictions.

\section{Materials and methods}

Bacterial strains

E. coli strain TGl was used for routine DNA manipulations. E. coli S17-1 (Simon et al. 1983) was used to mobilize pRK290 plasmid derivatives into $C$. crescentus by bacterial conjugation (Ely 1979). E. coli strain CI236 was used to prepare single-strand templates for site directed mutagenesis (Kunkel et al. 1987). C. crescentus NA1000 (Evinger and Agabian 1977) was used for 
cell synchrony and transcriptional studies, and its ampicillinsensitive and recombination-defective derivative, LS108 (Table 3) was used for Cori-plasmid replication studies.

Cell growth, synchrony, protein labeling, and immunoprecipitation

C. crescentus strains were grown in PYE medium (Poindexter 1964) or in M2G medium (Ely and Johnson 1977). pRK290-derived plasmids and pBluescript II-derived Cori plasmids were maintained in C. crescentus cultures by supplementing the media with $1 \mu \mathrm{g} / \mathrm{ml}$ of tetracycline or with $20 \mu \mathrm{g} / \mathrm{ml}$ of ampicillin, respectively. Cells were synchronized by collecting the more dense swarmer cells from a Ludox (colloidal silica) gradient and returning them to fresh $\mathrm{M} 2 \mathrm{G}$ medium (Evinger and Agabian 1977). Typically, 1 liter of M2G cultures $\mathrm{OD}_{660} 0.5-1.0$ was concentrated into $150 \mathrm{ml}$ by centrifugation before applying the Ludox protocol yielding $\sim 50 \mathrm{ml}$ of $\mathrm{OD}_{660}=0.4-0.8$ swarmer cells (>95\% pure, as judged by light microscopy). Protocols for labeling synchronous $C$. crescentus cells with $\left|{ }^{35} S\right|$ methionine and immunoprecipitating radiolabeled proteins have been described (Gomes and Shapiro 1984).

\section{Transcriptional analysis}

Transcription initiation at the hemE promoters was measured using $l a c Z$ transcriptional fusions containing translational stop codons in all three frames preceding the lac $Z$ ribosome-binding sites (Yu and Shapiro 1992). This allowed transcription passing through the $l a c Z$ gene to be measured indirectly by pulse-labeling $1.0 \mathrm{ml}$ of cells (containing the $\mathrm{pRK} 290 \mathrm{lacZ}$ constructs) with $0.01 \mathrm{mCi}$ of $\left[{ }^{35} \mathrm{~S}\right.$ ) methionine (Tran ${ }^{-35} \mathrm{~S}$-label, ICN Radiochemicals) for $5 \mathrm{~min}$, and immunoprecipitation with anti- $\beta$-galactosidase antibody (Gomes and Shapiro 1984). Polar transcription localization experiments were performed as reported (Gober et al. 199lbl, and nascent swarmer cells and stalked cells were isolated by combining the Ludox and differential centrifugation protocols (Gober and Shapiro 1992). $\beta$-Galactosidase assays were performed on unsynchronized exponential cultures $\mathrm{OD}_{660}=0.2-0.4$ of $C$. crescentus strain NA1000 containing the pRK290 lacZ reporter plasmids with Cori subclones (Fig. 2, constructs 1-16) as described (Miller 1972). For the primer extension analysis, $C$. crescentus RNA was prepared from exponentially growing NA1000 cells in M2G media by the hot phenol method (Gomes et al. 1990) and treated with ribonuclease-free DNase I, reextracted with 50:50 phenol/chloroform, ethanol precipitated, and resuspended in sterile water. Approximately 5 $\mu \mathrm{g}$ of this RNA was annealed with $\sim 100,000 \mathrm{cpm}$ of the specified hemE oligonucleotides (Fig. 3A,B), and $5^{\prime}$-end labeled with $\left[\gamma^{32} \mathrm{P} \mid \mathrm{ATP}\right.$ (Amersham) and T4 phage polynucleotide kinase. The primer extension reaction was performed with 5 units of avian myloblastosis vinus reverse transcriptase in the presence of actinomycin C, and the products were analyzed on a $6 \%$ polyacrylamide sequencing gel alongside dideoxynucleotide sequencing reactions.

Table 3. Strains and plasmids

\begin{tabular}{|c|c|c|}
\hline Strains/plasmids & Description & Reference/source \\
\hline \multicolumn{3}{|l|}{ E. coli } \\
\hline TG1 & $\Delta\left(\right.$ lac-pro), supE, thi, hsdD5/F' proAB, lacI $I^{4}, \operatorname{lac} Z \Delta \mathrm{M} 15$ & T.J. Gibson (unpubl.) \\
\hline S17-1 & E. coli $294:: \mathrm{RP} 4-2(\mathrm{Tc}:: \mathrm{Mu})(\mathrm{Km}:: \mathrm{Tn} 7)$ & Simon et al. (1983) \\
\hline CJ236 & dut1, ung1, thi, relA/ pCJ105 & Kunkel et al. (1987) \\
\hline \multicolumn{3}{|l|}{ C. crescentus } \\
\hline NAl000 & synchronizable wild type & Evinger and Agabian (1977) \\
\hline LS108 & NA1000 derivative bla::Tntet, rec $\sim \operatorname{Tn} 5$ & Marczynski and Shapiro (1992) \\
\hline \multicolumn{3}{|l|}{ Plasmids } \\
\hline pBluescript II & Amp, ColE1, KS polylinker & Stratagene \\
\hline pGM946 & wild-type Cori-plasmid, $1.7-\mathrm{kb}$ BamHI-HindIII Cori in pBluescript II & this paper \\
\hline \multicolumn{3}{|c|}{ 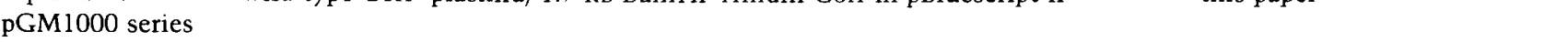 } \\
\hline $1001-1030$ & pGM946 with deletion/insertions & Table 1 \\
\hline $1031-1038$ & pGM946 with targeted mutations & Table 2 \\
\hline 1064 & pGM946 RK2 par, ClaI/CcrM sites & Fig. 7 \\
\hline 1065 & pGM1030 RK2 par, ClaI/CcrM sites & Fig. 7 \\
\hline pRK2901acZ & $\begin{array}{l}\text { derivative of broad host-range pRK290 (Ditta et al. 1980) with lacZ } \\
\text { transcriptional reporter and mp18 polylinker }\end{array}$ & Yu and Shapiro $(1992)$ \\
\hline \multicolumn{3}{|c|}{ - } \\
\hline 2001-2016 & pRK290lacZ containing Cori subclones & Fig. 2 \\
\hline $2021-2028$ & from pGM946 and pGM1000 series & Fig. 3 \\
\hline pJBZ281 & $l a c Z$ translational fusion vector & Alley et al. (1991) \\
\hline pGM3901 & $\begin{array}{l}\text { hemE::lacZ protein fusion plasmid, BgIII to HindIII Cori from pGM946 in } \\
\text { pJBZ281 }\end{array}$ & this paper \\
\hline pGM3902 & $\begin{array}{l}\text { hemE::lacZ protein fusion plasmid, EcoRI-HindIII Cori from pGM946 in } \\
\text { pJBZ281 }\end{array}$ & this paper \\
\hline \multicolumn{3}{|l|}{ pGM4000 series } \\
\hline 4001 & pGM3901 in EcoRI site of pRK290 & Fig. 8B \\
\hline 4002 & pGM3902 in EcoRI site of pRK290 & Fig. 8B \\
\hline 4003 & BglII-HindIII Cori in pRK290lacZ & Fig. 8B \\
\hline 4004 & EcoRI-HindII Cori in pRK290lacZ & Fig. 8B \\
\hline 4005 & EcoRI-HindIII $(+244)$ Cori from pGM1032 in pRK290lacZ & Fig. 8B \\
\hline
\end{tabular}


DNA preparation, sequencing, mutagenesis, and replication analysis

Alkaline lysis plasmid preparations from E. coli, digestions by restriction endonucleases, agarose gel electrophoresis, and Southern blot procedures were performed according to established protocols (Sambrook et al. 1989). DNA sequencing was performed by the dideoxynucleotide chain termination method (Sanger et al. 1977) using the Sequenase System II kit (U.S. Biochemicall. Single-strand DNA pBluescript II phagemids were prepared as described (Short et al. 1988). The series of Coriplasmid mutations (Tables 1 and 2) were created by combining the methods of Heffron et al. (1978) and Prentki and Krisch (1984). To create specific base pair changes, oligonucleotidedirected site-specific mutagenesis was performed as described (Kunkel et al. 1987). Cori DNA that was judged as unmutated on the basis of DNA sequencing analysis was used as a positive control. The ability of these plasmids to replicate autonomously in C. crescentus was assayed after electroporation (Fig. 1B; Gilchrist and Smit 1991), by quantitative extraction of plasmid DNA from C. crescentus (Fig. 1C; Marczynski et al. 1990) and by in vivo ${ }^{32}$ P-labeled DNA, as detailed previously (Marczynski and Shapiro 1992).

\section{Acknowledgments}

We thank Mimi Susskind for suggesting that the hemE weak promoter mRNA might be translated with a downstream box, Yves Brun and Janine Maddock for aid with hemE sequence analysis, and Bert Ely for sharing unpublished promoter consensus sequences. This investigation was supported by grant NP938B from the American Cancer Society.

The publication costs of this article were defrayed in part by payment of page charges. This article must therefore be hereby marked "advertisement" in accordance with 18 USC section 1734 solely to indicate this fact.

\section{References}

Alley, M.R.K., S.L. Gomes, W. Alexander, and L. Shapiro. 1991. Genetic analysis of a temporally transcribed chemotaxis gene cluster in Caulobacter crescentus. Genetics 129: 333342 .

Asai, T., M. Takanami, and M. Imai. 1990. The AT richness and gid transcription determine the left border of the replication origin of the E. coli chromosome. EMBO I. 9: 4065-4072.

Asai, T., C.-P. Chen, T. Nagata, M. Takanami, and M. Imai. 1992. Transcription in vivo within the replication origin of the Escherichia coli chromosome: A mechanism for activating initiation of replication. Mol. \& Gen. Genetics 231: 169178.

Bachmann, B.J. 1990. Linkage map of Escherichia coli K-12, Edition 8. Microbiol. Rev. 54: 130-197.

Baker, T.A. and A. Kornberg. 1988. Transcriptional activation of initiation of replication from the $E$. coli chromosomal origin: An RNA-DNA hybrid near oriC. Cell 55: 113-123.

Baker, T.A. and S.H. Wickner. 1992. Genetics and enzymology of DNA replication in Escherichia coli. Annu. Rev. Genet. 26: $447-477$.

Bramhill, D. and A. Kornberg. 1988a. Duplex opening by DnaA protein at novel sequences in initiation of replication at the origin of the E. coli chromosome. Cell 52: 743-755.

1988b. A model for initiation at origins of DNA replication. Cell 54: 915-918.

Brun, Y.V., G.T. Marczynski, and L. Shapiro. 1994. The expression of asymmetry during Caulobacter cell differentiation. Annu. Rev. Biochem. 63: 419-450.
Clayton, D.A. 1991. Replication and transcription of vertebrate mitochondrial DNA. Annu. Rev. Cell Biol. 7: 453-478.

DePamphilis, M.L. 1988. Transcriptional elements as components of eukaryotic origins of DNA replication. Cell 52: $635-638$.

de Zamaroczy, M., G. Faugeron-Fonty, G. Baldacci, R. Goursot, and G. Bernardi. 1984. The ori sequences of the mitochondrial genome of a wild-type yeast strain: Number, location, orientation and structure. Gene 32: 439-457.

Dingwall, A. and L. Shapiro. 1989. Rate, origin, and bidirectionality of Caulobacter chromosome replication as determined by pulsed-field gel electrophoresis. Proc. Natl. Acad. Sci. 86: $119-123$.

Ely, B. 1979. Transfer of drug resistance factors to the dimorphic bacterium Caulobacter crescentus. Genetics 91: 371-380.

- 1992. DNA sequence of the $3^{\prime}$ end of the Caulobacter crescentus 16S rRNA gene. Nucleic Acids Res. 20: 1423.

Ely, B. and R.C. Johnson. 1977. Generalized transduction in Caulobacter crescentus. Genetics 87: 391-399.

Evinger, M. and N. Agabian. 1977. Envelope-associated nucleoid from Caulobacter crescentus stalked and swarmer cells. 1. Bacteriol. 132: 294-301.

1979. Caulobacter crescentus nucleoid: Analysis of sedimentation behavior and protein composition during the cell cycle. Proc. Natl. Acad. Sci. 76: 175-178

Gilchrist, A. and J. Smit. 1991. Transformation of freshwater and marine Caulobacters by electroporation. I. Bacteriol. 173: 921-925.

Gober, J.W. and L. Shapiro. 1990. Integration host factor is required for the activation of developmentally regulated genes in Caulobacter. Genes \& Dev. 4: 1494-1504.

- 1992. A developmeritally regulated Caulobacter Flagellar promoter is activated by 3 ' enhancer and IHF binding elements. Mol. Biol. Cell 3: 913-926.

Gober, I.W., M.R. Alley, and L. Shapiro. 1991a. Positional information during Caulobacter cell differentiation. Curr. Opin. Genet. Dev. 1: 324-329.

Gober, J.W., R. Champer, S. Reuter, and L. Shapiro. 1991b. Expression of positional information during cell differentiation in Caulobacter. Cell 64: 381-391.

Gomes, S.L. and L. Shapiro. 1984. Differential expression and position of chemotaxis methylation proteins in Caulobacter crescentus. J. Mol. Biol. 178: 551-568.

Gomes, S.L., J.W. Gober, and L. Shapiro. 1990. Expression of Caulobacter heat shock dnaK is developmentally controlled during growth at normal temperatures. I. Bacteriol. 172: 3051-3059.

Guo, Z. and M.L. DePamphilis. 1992. Specific transcription factors stimulate simian virus 40 and polyomavirus origins of DNA replication. Mol. Cell. Biol. 12: 2514-2524.

Heffron, F., M. So, and B.J. McCarthy. 1978. In vitro mutagenesis of a circular DNA molecule by using synthetic restriction sites. Proc. Natl. Acad. Sci. 75: 6012-6016.

Heintz, N.H., L. Dailey, P. Held, and N.H. Heintz. 1992. Eukaryotic replication origins as promoters of bidirectional DNA synthesis. Trends Genet. 8: 376-381.

Kornberg, A. and T.A. Baker. 1992. DNA replication. W.H. Freeman, New York.

Kowalski, D. and M.J. Eddy. 1989. The DNA unwinding element: A novel, cis-acting component that facilitates opening of the Escherichia coli replication origin. EMBO I. 8: 43354344 .

Kues, U. and U. Stahl. 1989. Replication of plasmids in gramnegative bacteria. Microbiol. Rev. 53: 491-516.

Kunkel, T.A., I.D. Roberts, and R.A. Zakour. 1987. Rapid and efficient site-specific mutagenesis without phenotypic selec- 
tion. Methods Enzymol. 154: 367-382.

Kustu, S., A.K. North, and D.S. Weiss. 1991. Prokaryotic transcriptional enhancers and enhancer-binding proteins. Trends Biochem. Sci. 16: 397-402.

Leong, S.A., P.H. Williams, and G.S. Ditta. 1985. Analysis of the $5^{\prime}$ regulatory region of the gene for $\delta$-aminolevulinic acid synthetase of Rhizobium meliloti. Nucleic Acids Res. 13: 5965-5976.

Li, R. and M.R. Botchan. 1993. The acidic transcriptional activation domains of VP16 and p53 bind the cellular replication protein A and stimulate in vitro BPV-1 DNA replication. Cell 73: 1207-1221.

Lobner-Olesen, A. and E. Boye 1992. Different effects of mioC transcription on initiation of chromosomal and minichromosomal replication in Escherichia coli. Nucleic Acids Res. 20: 3029-3036.

Lott, T., N. Ohta, and A. Newton. 1987. Order of gene replication in Caulobacter crescentus; Use of in vivo labeled genomic DNA as a probe. Mol. \& Gen. Genet. 210: 543-550.

Marahrens, Y. and B. Stillman. 1992. A Yeast chromosomal origin of DNA replication defined by multiple functional elements. Science 255: 817-823.

Marczynski, G.T. and L. Shapiro. 1992. Cell-cycle control of a cloned chromosomal origin of replication from Caulobacter crescentus. J. Mol. Biol. 226: 959-977.

Marczynski, G.T., A. Dingwall, and L. Shapiro. 1990. Plasmid and chromosomal DNA replication and partitioning during the Caulobacter crescentus cell cycle. I. Mol. Biol. 212: 709-722.

Masukata, H. and J.-I. Tomizawa. 1990. A mechanism of formation of a persistent hybrid between elongating RNA and template DNA. Cell 62: 331-338.

Miller, J.H. 1972. Experiments in molecular genetics. Cold Spring Harbor Laboratory, Cold Spring Harbor, New York.

Mitchell, P.J. and R. Tjian. 1989. Transcriptional regulation in mammalian cells by sequence-specific DNA binding proteins. Science 245: 371-378.

Newton, A. and N. Ohta. 1990. Regulation of the cell division cycle and differentiation in bacteria. Annu. Rev. Microbiol. 44: 689-719.

Ogawa, T. and T. Okazaki. 1994. Cell cycle-dependent transcription from the gidA and mioC promoters of Escherichia coli. J. Bacteriol. 176: 1609-1615.

Ogawa, T., T.A. Baker, A. van der Ende, and A. Kornberg. 1985. Initiation of enzymatic replication at the origin of Escherichia coli chromosome: Contributions of RNA polymerase and primase. Proc. Natl. Acad. Sci. 82: 3562-3568.

Oka, A., K. Sugimoto, and M. Takanami. 1980. Replication origin of the Escherichia coli K-12 chromosome: The size and structure of the minimum DNA segment carrying the information for autonomous replication. Mol. \& Gen. Genet. 178: 9-20.

Oka, A., H. Sasaki, K. Sugimoto, and M. Takanami. 1984. Sequence organization of replication origin of the Escherichia coli K-12 chromosome. J. Mol. Biol. 176: 443-458.

Poindexter, J.S. 1964. Biological properties and classification of the Caulobacter group. Bacteriol. Rev. 28: 231-295.

Prentki, P. and H.M. Krisch. 1984. In vitro insertion mutagenesis with a selectable DNA fragment. Gene 29: 303-313.

Roberts, R.C., R. Burioni, and D.R. Helinski. 1990. Genetic characterization of the stability functions of a region of broad-host-range plasmid RK2. I. Bacteriol. 172: 6204-6216.

Roeder, R.G. 1991. The complexities of eukaryotic transcription initiation: Regulation of preinitiation complex assembly. Trends Biochem. Sci. 16: 402-408.

Romeo, P.-H., N. Raich, A. Dubart, D. Beaupain, M. Pryor, J. Kushner, M. Cohen-Solal, and M. Goossens. 1986. Molecu- lar cloning and nucleotide sequence of a complete human uroporphyrinogen decarboxylase cDNA. I. Biol. Chem. 261: 9825-9831.

Sambrook, J., E.F. Fritsch, and T. Maniatis. 1989. Molecular cloning. Cold Spring Harbor Laboratory Press, Cold Spring Harbor, New York.

Sanger, F., S. Nicklen, and A.R. Coulson. 1977. DNA sequencing with chain-terminating inhibitors. Proc. Natl. Acad. Sci. 74: 5463-5467.

Schinkel, A.H. and H.F. Tabak. 1989. Mitochondrial RNA polymerase: Dual role in transcription and replication. Trends Genet. 5: 149-154.

Schmidt, T.M., E.F. DeLong, and N.R. Pace. 1991. Analysis of a marine picoplankton community by 16S rRNA gene cloning and sequencing. I. Bacteriol. 173: 4371-4378.

Schmitt, M.E. and D.A. Clayton. 1993. Conserved features of yeast and mammalian mitochondrial DNA replication. Curr. Opin. Genet. Dev. 3: 769-774.

Shean, C.S. and M.E. Gottesman. 1992. Translation of the prophage $\lambda c I$ transcript. Cell 70: 513-522.

Short, J.M., J.M. Fernandez, J.A. Sorge, and W.D. Huse. 1988. $\lambda Z A P: A$ bacteriophage $\lambda$ expression vector with in vivo excision properties. Nucleic Acids Res. 16: 7583-7600.

Simon, R., U. Priefer, and A. Puhler. 1983. A broad host range mobilization system for in vivo genetric engineering: Transposon mutagenesis in gram-negative bacteria. Biotechnology 1: 784-791.

Skarstad, K., T.A. Baker, and A. Kornberg. 1990. Strand separation required for initiation of replication at the chromosomal origin of $E$. coli is facilitated by a distant RNA-DNA hybrid. EMBO I. 9: 2341-2348.

Sprengart, M.L., H.P. Fatscher, and E. Fuchs. 1990. The initiation of translation in E. coli: Apparent base pairing between the 16S rRNA and downstream sequences of the mRNA. Nucleic Acids Res. 18: 1719-1723.

Stahl, D.A., R. Key, B. Flesher, and I. Smit. 1992. The phylogeny of marine and freshwater Caulobacters reflects their habitat. I. Bacteriol. 174: 2193-2198.

Swoboda, U.K., C.S. Dow, and L. Vitkovic. 1982. Nucleoids of Caulobacter crescentus CB15. I. Gen. Microbiol. 128: 279289.

Theisen, P.W., J.E. Grimwade, A.C. Leonard, J.A. Bogan, and C.E. Helmstetter. 1993. Correlation of gene transcription with the time of initiation of chromosome replication in Escherichia coli. Mol. Microbiol. 10: 575-584.

Wingrove, J.A., E.K. Mangan, and J.W. Gober. 1993. Spatial and temporal phosphorylation of a transcriptional activator regulates pole-specific gene expression in Caulobacter. Genes \& Dev. 7: 979-1992.

Woese, C.R. 1987. Bacterial evolution. Microbiol. Rev. 51: $221-$ 271.

Yang, D., Y. Oyaizu, H. Oyaizu, G.J. Olsen, and C.R. Woese. 1985. Mitochondrial origins. Proc. Natl. Acad. Sci. 82: 4443-4447.

Yoshikawa, H. and N. Ogasawara. 1991. Structure and function of DnaA and the DnaA-box in eubacteria: Evolutionary relationships of bacterial replication origins. Mol. Microbiol. 5: 2589-2697.

Yu, J. and L. Shapiro. 1992. Early Caulobacter crescentus genes fliL and fliM are required for flagellar gene expression and normal cell division. J. Bacteriol. 174: 3327-3338.

Zweiger, G. and L. Shapiro. 1994. Expression of Caulobacter dnaA as a function of the cell cycle. J. Bacteriol. 176: 401-408.

Zweiger, G., G.T. Marczynski, and L. Shapiro. 1994. A Caulobacter methyltransferase that only functions in the predivisional cell. J. Mol. Biol. 235: 472-485. 


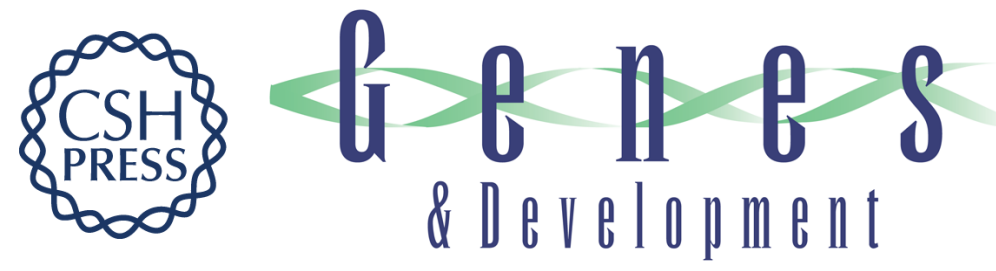

\section{A developmentally regulated chromosomal origin of replication uses essential transcription elements.}

G T Marczynski, K Lentine and L Shapiro

Genes Dev. 1995, 9:

Access the most recent version at doi:10.1101/gad.9.12.1543

References This article cites 70 articles, 28 of which can be accessed free at:

http://genesdev.cshlp.org/content/9/12/1543.full.html\#ref-list-1

License

Email Alerting

Service

Receive free email alerts when new articles cite this article - sign up in the box at the top right corner of the article or click here.

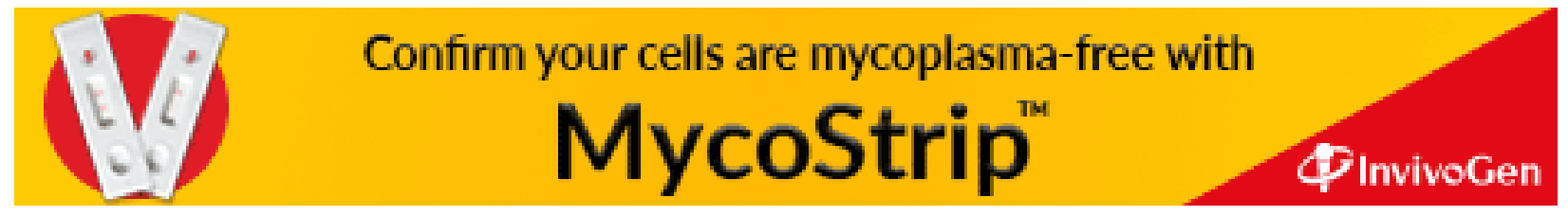

